\title{
Overconfidence, Investor Sentiment, and Evolution
}

\author{
F. Albert Wang ${ }^{1}$ \\ Jesse H. Jones Graduate School of Management, Rice University, MS 531, Houston, Texas 77005 \\ E-mail: wangfa@rice.edu \\ URL: http://www.ruf.rice.edu/ wangfa
}

Received June 5, 2000

\begin{abstract}
We examine the survival of nonrational investors in an evolutionary game model with a population dynamic for a large economy. The dynamic indicates that the growth rate of wealth accumulation drives the evolutionary process. We focus our analysis on the survival of overconfidence and investor sentiment. We find that underconfidence or pessimism cannot survive, but moderate overconfidence or optimism can survive and even dominate, particularly when the fundamental risk is large. These findings provide new empirical implications for the survivability of active fund management. Our results lend support to the relevance of the psychology of investors in studying financial markets. Journal of Economic Literature Classification Numbers: G10, G14. ( 2001 Academic Press
\end{abstract}

Key Words: survival; overconfidence; investor sentiment; evolution; population dynamic.

In recent years, there has been a growing interest in studying the behavior and effects of nonrational investors, who misperceive the distribution of asset values, in financial markets. In these studies, there is an implicit assumption that nonrational investors are relevant and even critical for the study of financial markets. There are, however, two opposing views on the relevance of this issue in the literature. On the one hand, Black (1986) argues that if all investors are rational and perceive their information correctly, then there will be very little trading in individual assets since it is in the interest of informed traders not to trade with each other (see also Milgrom and Stokey (1982)). Furthermore, if there is little trading and liquidity in individual assets, then it will be difficult to price index funds and derivative assets.

${ }^{1}$ This paper is a significantly revised and retitled version of my earlier working paper, "Overconfidence, Deligated Fund Management, and Survival." I thank Nick Barberis, Jeff Fleming, Jim Friedman, Simon Gervais, Pete Kyle, Robert Shiller, Andrei Shleifer, Anjan Thakor (the editor), Richard Thaler, two anonymous referees, and the seminar participants at the 1997 NBER Behavioral Finance Program Meeting, the 1997 and 1998 Western Finance Meetings, the Fourth Annual Conference of the Chicago Quantitative Alliance, IMF, and Rice University for helpful discussions and comments. The usual caveat applies. 
Therefore, the entire financial market cannot function properly without liquidity in individual assets. Black then posits that noise traders, who misperceive their noise as information, provide the necessary liquidity to the market. As a result, informed traders now have incentive to trade and their information is thus incorporated into prices. In essence, the whole structure of financial markets depends on the very presence of these noise traders. On the other hand, Friedman (1953) argues that nonrational investors are irrelevant because they will be driven out of the market by rational investors eventually in the process of natural selection. In this paper, we draw a line between the two opposing views by examining the viability of nonrational investors and, in particular, the survival of overconfidence and investor sentiment. If nonrational investors could not survive in the long run, then their impact on asset prices and markets would be at best transient. On the other hand, if nonrational investors could survive, it would then lend support to the relevance of the psychology of investors in studying financial markets. Thus, the key question we confront is whether nonrational investors can survive in the long run.

In order to examine the survival issue under a natural selection process, we consider the approach of evolutionary game theory since it is designed to analyze the survival of interactive agents in the evolutionary sense (Maynard Smith (1982) and Friedman (1991)). In our model, the choice of rational or nonrational types is formulated as a pure strategy in the evolutionary game. The evolution of the population of investor type is essentially driven by the relative fitness of the two strategies in terms of their current payoffs. In this context, we examine the longrun steady state of the population distribution between rational and nonrational investors in the market.

While the general evolutionary framework can apply to a variety of cases, we focus on two common scenarios. In the first scenario, we consider pairwise contests where every round of interaction involves two randomly matched individual investors who play a bilateral game in normal form. This scenario captures the strategic element in markets with imperfect competition. This setup is appropriate for analyzing the kind of markets where there exist a few big players with significant market power. In the second scenario, we examine playing-the-field contests where a large number of investors interact jointly in the market and yet none of them have market power. This scenario is relevant for studying the competitive market where all investors are price takers. In this paper, we adopt the first scenario to analyze the survival of overconfident traders with market power as described in Kyle and Wang (1997) and the second scenario for the survival of noise traders without market power as described in De Long, Shleifer, Summers, and Waldmann (henceforth DSSW) (1990). Both Kyle and Wang (1997) and DSSW (1990) deal with static models in which the population share is fixed, and hence the models are inadequate to address the long-run survival issue. In this paper, we extend these static models into evolutionary game models and examine the resulting population dynamic of nonrational traders according to their relative fitness in the game.

The population dynamic that emerges from the two models yields remarkably similar results regarding the survival of nonrational traders as a group. First, 
nonrational traders with negative sentiment will never survive in the long run. This applies to underconfidence in Kyle and Wang (1997) and to bearishness in DSSW (1990). Second, nonrational traders with extremely positive sentiment may not survive either. This applies to excessive overconfidence in Kyle and Wang (1997) and to excessive bullishness in DSSW (1990). Third, nonrational traders with moderately positive sentiment tend to dominate the market, particularly when the variance of the risky asset's value (which we call the "fundamental" risk) is large.

Note that aggressive trading tends to create a large price impact. Moderate sentiment and large fundamental risk both serve to reduce the adverse price impact. As a result, individual nonrational traders may bankrupt sooner than individual rational traders because of the price risk (Samuelson $(1971,1977)$ ). But, nonrational traders as a group with a higher expected return can still accumulate wealth at a higher speed than rational traders and hence increase in population. It is in this spirit that we demonstrate the survival of nonrational traders as a group, rather than as individuals.

It is important to note that the economic rationale for the survival of overconfidence in Kyle and Wang (1997) is different from that for the survival of the bullish sentiment in DSSW (1990). In the latter case, the bullish sentiment causes noise traders to hold more of the risky asset than their rational opponents, thus gaining a higher expected return. In the former case, however, there is no such risk premium, given that all traders are assumed to be risk neutral. Instead, overconfidence leads investors to buy more of the asset when the traders receive good signals and to sell more of the asset with bad signals. As a result, the demand differential between the overconfident traders and their rational opponents tends to be positively correlated with the asset's value, thus yielding a higher expected return to the overconfident traders.

Some recent attempts addressing the survival issue include DSSW (1991), Blume and Easley (1992), Palomino (1996), Wang (1998), and Hirshleifer and Luo (2001). DSSW (1991) study the wealth accumulation process for traders, but they assume the risky assets' supplies to be infinitely elastic and the returns to be exogenously given. As a result, while investors' beliefs affect their demands for risky assets, they do not affect the prices of the risky assets. This is in sharp contrast to our model where both investors' demands and the equilibrium price are influenced by their beliefs.

Blume and Easley (1992) find that nonrational traders can survive better than rational traders if nonrational traders' utility is closer to log-utility than their rational opponents'. The survival of nonrational traders in this model is due to systematic differences in utility functions. On the one hand, our results capture the same effect of the utility-based argument in the sense that overconfidence and bullish sentiment make nonrational traders trade more aggressively like log-utility traders. On the other hand, the aggressiveness in our model comes from irrational beliefs, rather than different utility functions. Essentially, our paper shows that given the same utility functions, nonrational investors can still survive if their irrational beliefs make them trade more aggressively in the right way. 
Moreover, in the case of overconfidence (Kyle and Wang (1997)), both rational and nonrational traders are risk-neutral and hence both trade more aggressively than log utility traders do, but still we show that moderate overconfident traders can survive better than their rational opponents. Palomino (1996) finds that spiteful noise traders may earn a higher expected utility than their rational opponents do and eventually dominate the market. In contrast, our model does not assume spiteful behavior for nonrational investors.

Wang (1998) extends Kyle (1985) by incorporating overconfidence into the dynamic model of insider trading. He shows that the overconfident insider trades more aggressively than he or she would if he or she were rational. In anticipating such aggressive informed trading, market makers reduce liquidity. This, in turn, generates greater profits for the overconfident insider at the expense the liquidity traders. This result implies that overconfidence can help a monopolistic insider amass even greater wealth and power, thus strengthening his or her dominance in the market.

Hirshleifer and Luo (2001) consider a population dynamic based on imitation of the recent profit in a competitive market. They find that risk-averse overconfident traders take on more risk and hence earn higher profits than rational traders do. Both Wang (1998) and our paper show that overconfident traders can still make higher profits without such a risk premium and eventually come to dominate the market.

Most important, while our survival analysis is much in the spirit of the previous literature, this paper takes a further step forward by explicitly modeling the wealth accumulation process that emerges from the market competition between the group of rational investors and the group of nonrational investors in a large economy. As a result, the population dynamic examined in this paper does not depend on individual adaptation as has often been assumed in previous literature. The endogenously determined group wealth accumulation process thereby distinguishes the current paper from much of the previous literature with exogenous imitation processes.

The plan of this paper is as follows. Section I develops a general population dynamic between rational and nonrational traders in a large economy. The population dynamic conforms to the replicator dynamic in a standard evolutionary game. Section II examines the survival of overconfidence in a pairwise contest based on the trading mechanism in Kyle and Wang (1997). Section III examines the survival of investor sentiment in a playing-the-field contest based on the trading mechanism in DSSW (1990). Section IV discusses the robustness and implications of our models and analysis. Section V concludes. All proofs are in the Appendix.

\section{POPULATION DYNAMIC IN ASSET MARKETS}

\section{A. The General Framework}

Consider a large population of individual traders who have two strategies (or phenotypes) available: rational strategy (type-1) and nonrational strategy (type-2). 
At any time $t$, let $M_{i}(t)$ be the number of individual traders who adopt strategy (type) $i \in\{1,2\}$. The associated population profile is therefore defined as the ordered pair $x(t)=\left(x_{1}(t), x_{2}(t)\right)$, where $x_{i}(t)=M_{i}(t) /\left(M_{1}(t)+M_{2}(t)\right)$ is the population share of type- $i$ traders. The population state $x(t)$ is thus identified with a mixedstrategy in the associated strategy simplex $\Delta$ such that $x(t) \in \Delta=\left\{x(t) \in R_{+}^{2} \mid\right.$ $\left.x_{1}(t)+x_{2}(t)=1\right\}$. Each strategy induces a payoff for the individual trader who adopts it, given the strategy profile of the rest of the population. Let the payoff to any pure strategy $i \in\{1,2\}$, given the population state $x(t)$, be denoted as $u(i, x(t))$. The average payoff to an individual trader drawn at random from the population is thus given by $u(x(t), x(t))=\sum_{i=1}^{2} x_{i}(t) \cdot u(i, x(t))$.

Following the approach in evolutionary games, let current payoffs be the determining factor for the relative fitness of different strategies and, as a result, drive the evolution of their corresponding population shares. In other words, current payoffs from trading activities represent the incremental effect on the fitness of different types, measured as the number of each type of trader. All other factors that are independent of the current payoffs affect only the absolute fitness of each type, but not the relative fitness of different strategies. Let the net birthrate $\kappa$ at any time $t$ represent these other factors as background fitness independent of the current payoffs and let the population of traders evolve continuously over time. This setup results in the following population dynamic for type- $i$ traders,

$$
\dot{M}_{i}(t)=[\kappa+u(i, x(t))] M_{i}(t)
$$

where $\dot{M}_{i}(t)$ is the instantaneous rate of the change in the population of type- $i$ traders at time $t$. The corresponding dynamic for the population share of type- $i$ traders $x_{i}(t)$ is straightforward to calculate and obtained as follows:

$$
\dot{x}_{i}(t)=[u(i, x(t))-u(x(t), x(t))] x_{i}(t) .
$$

This dynamic implies that the type of traders associated with better-than-average payoffs increases, while the type associated with worse-than-average payoffs decreases in the process of evolution. As expected, this dynamic is independent of the common background fitness measure, i.e., net birthrate $\kappa$. It is worth nothing that the dynamic exhibits the same form of the usual replicator dynamic (Taylor and Jonker (1978)) in evolutionary games. So far, we derive a general population dynamic without specifying a particular payoff function. Clearly, the dynamic depends on the choice of the payoff function, which in turn depends on the asset market in question. In Section B, we show that in a large economy the investment return of each strategy (type) emerges as the strategy's (type's) payoff function for the population dynamic in the process of wealth accumulation. 


\section{B. The Population Dynamic in a Large Economy}

Consider a large economy with a sufficiently large number of risky asset markets, $N$. In each period $t(t=1,2, \ldots)$, the $N$ risky assets' returns, denoted by $\tilde{r}_{1}, \tilde{r}_{2}, \ldots, \tilde{r}_{N}$, are independently and identically distributed across markets. Each asset market $n(n=1,2, \ldots, N)$ has two types of traders, denoted by $i=1,2$. Type- 1 traders are those who have correct beliefs about the distributions of risky assets $n$ in the market, whereas type- 2 traders are those who misperceive the distributions of the risky asset due to cognitive errors (Kahneman et al. (1982)). In this sense, type- 1 traders are rational and type- 2 traders are nonrational. All traders are endowed with a constant capital $c_{0}$ at the beginning of each period and may borrow or lend at a nonnegative riskfree rate $r$. In each period, individual type- $i$ traders in asset market $n$ choose their optimal demand $q_{i, n}$ for risky asset $n$ to maximize their expected utility of the end-of-period wealth, given the current market price $p_{n}$ and their beliefs and information. At the end of the period, asset $n$ 's return $r_{n}$ is realized and the type- $i$ trader's investment return, denoted by $R_{i, n}$, is given by

$$
R_{i, n}=\alpha_{i, n} r_{n}+\left(1-\alpha_{i, n}\right) r, \quad \text { where } \alpha_{i, n}=\frac{p_{n} q_{i, n}}{c_{0}} \text { is the weight in risky }
$$

asset $n$ for the type- $i$ trader.

The end-of-period wealth of type- $i$ traders as a group is the sum of the realized end-of-period wealth of all individual type- $i$ traders across $n$ markets. Let $w_{i}(t) \equiv$ $c_{0} \cdot M_{i}(t)$ be the wealth of type-i traders as a group at the beginning of period $t$. The population share of the type- $i$ traders as a group in period $t, x_{i}(t)$, is therefore determined by its wealth share at time $t, x_{i}(t)=w_{i}(t) /\left(w_{1}(t)+w_{2}(t)\right)$, for $i=1$, 2 . This captures the notion that the more wealth a group has the more populous that group becomes. The distinction between wealth, $w_{i}(t)$, and population share, $x_{i}(t)$, is important because a group of traders can have positive wealth and yet become extinct in terms of its population share, when the group's speed of accumulating wealth is of a lower order relative to the other group. In order to emphasize the dependence of individual traders' returns on the population state, write $\tilde{R}_{i, n}(x(t))$ as the return of individual type- $i$ traders in market $n$, given the current population state $x(t)$. Similarly, write $\bar{R}_{i}(x(t)) \equiv \sum_{n=1}^{N} b_{i, n} \tilde{R}_{i, n}(x(t))$ as the average return of type- $i$ traders across markets in period $t$, where the weight $b_{i, n}$ is the relative size of type- $i$ traders in market $n$ such that the weights across markets sum to one; i.e., $\sum_{n=1}^{N} b_{i, n}=1$. In other words, the average return obtained by a given trader type depends not only on the return he or she achieves in each market, $\tilde{R}_{i, n}(x(t))$, but also on his or her relative size in each of those markets, $b_{i, n}$.

The wealth of type- $i$ traders as a group at the beginning of period $t+1$ is therefore given by

$$
w_{i}(t+1)=w_{i}(t)\left[1+\bar{R}_{i}(x(t))\right]=c_{0} \cdot M_{i}(t+1) .
$$


Now, consider a "smooth" continuous-time counterpart of the above discretetime wealth accumulation process such that at any fraction $\delta$ of the period, the wealth of type- $i$ traders as a group at time $t+\delta$ is given by

$$
w_{i}(t+\delta)=w_{i}(t)\left[1+\delta \bar{R}_{i}(x(t))\right], \quad \text { where } 0 \leq \delta \leq 1 .
$$

Consequently, the population share of type- $i$ traders as a group at time $t+\delta$ is given by

$$
x_{i}(t+\delta)=\frac{w_{i}(t+\delta)}{\sum_{j=1}^{2} w_{j}(t+\delta)}=\frac{x_{i}(t)\left[1+\delta \cdot \bar{R}_{i}(x(t))\right]}{\sum_{j=1}^{2} x_{j}(t)\left[1+\delta \cdot \bar{R}_{j}(x(t))\right]}
$$

The instantaneous rate of the change in population share at time $t$, denoted by $\dot{x}_{i}(t)$, is obtained as follows:

$$
\begin{gathered}
\dot{x}_{i}(t) \equiv \lim _{\delta \rightarrow 0} \frac{x_{i}(t+\delta)-x_{i}(t)}{\delta}=x_{i}(t)\left(1-x_{i}(t)\right)\left[\bar{R}_{i}(x(t))-\bar{R}_{j}(x(t))\right] \\
=x_{i}(t)\left[\bar{R}_{i}(x(t))-\overline{\bar{R}}(x(t))\right], \quad \text { for } i, j=1,2 \quad \text { and } \quad i \neq j, \quad \text { and } \\
\overline{\bar{R}}(x(t)) \equiv \sum_{i=1}^{2} x_{i}(t) \cdot \bar{R}_{i}(x(t))
\end{gathered}
$$

This dynamic indicates that the growth rate, $\dot{x}_{i}(t) / x_{i}(t)$, of group $i$ 's population share equals the difference between the group's average return across all markets, $\bar{R}_{i}(x(t))$, and the population-share weighted average return of all traders in the economy, $\overline{\bar{R}}(x(t))$. This population dynamic emerges from the process of asset accumulation and it shows that the investment return of different strategies (types) drives the evolutionary process in asset markets. When compared to the dynamic in (2), the dynamic in (7) indicates that the investment return of each strategy (type) is the strategy's (type's) payoff function for the population dynamic. Intuitively, this dynamic captures the spirit in real-world asset markets in the sense that the rise and fall of investment funds depend on their relative return performance in the markets (Lakonishok et al. (1992)). This process is also consistent with the practice in real life in the sense that old investors die and new investors inherit money and the strategies of their parent investors.

In general, the analysis of the stochastic process of the population dynamic in (7) is complex, because the average investment return of type- $i$ traders, i.e., $\bar{R}_{i}(x(t))$, depends on individual type- $i$ traders' return in each market $n$, i.e., $\tilde{R}_{i, n}(x(t))$, which is stochastic. However, if type- $i$ traders' size-adjusted returns, i.e., $b_{i, n} \tilde{R}_{i, n}(x(t))$, are independently distributed with finite variances across markets, then the average return of type- $i$ traders across markets converges to the expected return of a representative type- $i$ trader, denoted by $E\left[\tilde{R}_{i}(x(t))\right]$, as the number of markets, $N$, 
becomes sufficiently large (see Shiryayev (1984, p. 364)). That is,

$$
\bar{R}_{i}(x(t)) \equiv \sum_{n=1}^{N} b_{i, n} \tilde{R}_{i, n}(x(t)) \rightarrow E\left[\tilde{R}_{i}(x(t))\right], \quad \text { as } N \rightarrow \infty, \quad \text { for } i=1,2 .
$$

Since we consider an economy where the number of markets is sufficiently large and the risky assets' returns are independently and identically distributed across markets, the above convergence result in (8) naturally holds in our model. We drop the subscript $n$ in the RHS of (8), since the expectations are identical for all $n$. In such a large economy, the general population dynamic in (7) therefore becomes the following:

$$
\begin{gathered}
\dot{x}_{i}(t)=x_{i}(t)\left(1-x_{i}(t)\right)\left(E\left[\tilde{R}_{i}(x(t))\right]-E\left[\tilde{R}_{j}(x(t))\right]\right), \\
\text { for } i, j=1,2 \text { and } i \neq j .
\end{gathered}
$$

The population dynamic in (9) shows that in a large economy the instantaneous rate of change in the population share depends on the current expected return differential between the two types of traders, i.e., $E\left[\tilde{R}_{i}(x(t))\right]-E\left[\tilde{R}_{j}(x(t))\right]$, which, in turn, depends on the current population state, $x(t)$. In other words, the expected returns depend on the current population state and, at the same time, the change in the current population state depends on the expected returns. Such a dynamic relationship is important in real-world markets, because although higher expected returns tend to generate a greater population share, the greater population share up to a certain level may hurt the expected returns in the future. Hence, it is important to determine simultaneously the population shares and the expected returns in a dynamic system as in (9). This is in contrast to the imitation process of DSSW (1990) where the returns are calculated under the assumption that the noise trader share is fixed. Moreover, our endogenously determined group wealth accumulation process distinguishes our population dynamic from other dynamics based on exogenously chosen individual imitation process as in DSSW (1990).

So far, we develop the population dynamic between rational and nonrational traders without specifying any particular kind of nonrational traders and show that their survival depends on the relative fitness as measured by their current expected return. In order to examine the survival of a particular kind of irrationality, one needs to model the trading game between the two types of traders and derive their corresponding payoffs, i.e., the expected returns, as a function of current population state. This is what we turn to in the next two sections. Section II examines the survival of overconfidence in a pairwise contest and Section III examines the survival of investor sentiment in a playing-the-field contest. 


\section{OVERCONFIDENCE IN A PAIRWISE CONTEST}

In this section, we consider overconfident traders with market power in a pairwise contest. Consider a large economy with $N$ risky assets, whose values $\tilde{v}_{1}, \tilde{v}_{2}, \ldots, \tilde{v}_{N}$ are independently and identically distributed at the end of each period. For simplicity, normalize the risk-free rate $r$ to zero. The economy is populated with risk-neutral informed traders of two possible types: rational and nonrational. At the beginning of each period, informed traders do not know which type of the other informed traders they are going to face, since they have the possibility of trading against rational and nonrational traders. Then, nature draws randomly a pair of informed traders from the current distribution of the population for each market $n(n=1,2, \ldots, N)$, independently across all $N$ markets. Thus, in each market there are four possible type combinations of the two informed traders thus drawn. Denote the possible type combinations by $\left(i_{n}, j_{n}\right) \in\{(1,1)$, $(1,2),(2,1),(2,2)\}$, where $\left(i_{n}, j_{n}\right)=(1,2)$ means that the first informed trader drawn in market $n$ is a type-1 (rational) trader and the second informed trader is a type-2 (nonrational) trader, etc. The probability of each type-combination drawn in each market is governed by the current population state $x(t)=\left(x_{1}(t)\right.$, $\left.x_{2}(t)\right)$ in the large economy. Specifically, with probability $\left(x_{1}(t)\right)^{2}$ the pair of informed traders thus drawn is both rational, with probability $x_{1}(t) \cdot x_{2}(t)$ the pair of informed traders consists of one rational and one nonrational, etc.

In each period, after a particular type combination $\left(i_{n}, j_{n}\right)$ is thus drawn in market $n$, it becomes common knowledge to all market participants. These two informed traders then participate in one-shot trading along with liquidity traders and market makers in the market, based on the trading mechanism of Kyle and Wang $(1997)^{2}$. For simplicity, we suppress the time index $t$ in what follows, but it should be understood that all random variables discussed below depend on it. Informed trader $j(j=1,2)$ drawn in market $n$ has a unique access to a private signal $\tilde{s}_{j, n}$ about the asset's value $\tilde{v}_{n}$ in the market. The correct distribution of the signal is $\tilde{s}_{j, n}=\tilde{v}_{n}+\tilde{e}_{j, n}$. The forecast errors $\tilde{e}_{j, n}$ 's are independently and identically distributed for $j=1,2$ and $n=1,2, \ldots, N$. However, the informed trader's belief about his or her signal depends on his or her type. In particular, informed trader $j$ thinks his signal is $\tilde{s}_{j, n}=\tilde{v}_{n}+K_{j} \tilde{e}_{j, n}$. If the trader is rational, his or her belief reflects the correct distribution, i.e., $K_{j}=1$. On the other hand, if the trader is not rational, then his or her subjective belief is parameterized by $K_{j}=$ $K$, where $K$ is a nonnegative misperception parameter such that $K \neq 1$. Furthermore, a nonrational trader is overconfident if his or her subjective distribution is too tight, i.e., $0 \leq K<1$, or underconfident if it is too loose, i.e., $K>1$ (Oskamp (1965), Alpert and Raiffa (1959), Einhorn and Hogarth (1978)).

With risk-neutrality, informed trader $j$ submits a market order $\tilde{q}_{j, n}=q_{j, n}\left(\tilde{s}_{j, n}\right)$ to maximize his or her conditional expected trading profit, $\tilde{\Pi}_{j, n}$, given his private

${ }^{2}$ See Hirshleifer et al. (1994), Wang (1998), Odean (1998), and Daniel et al. (1998, 2000) for other overconfident trading models. 
signal $\tilde{s}_{j, n}$, i.e.,

$$
\begin{gathered}
\operatorname{Max}_{q_{j, n}} E\left[\tilde{\Pi}_{j, n} \mid \tilde{s}_{j, n}=s_{j, n}\right]=E\left[\left(\tilde{v}_{n}-\tilde{p}_{n}\right) \tilde{q}_{j, n} \mid \tilde{s}_{j, n}=s_{j, n}\right], \\
\text { for } j=1,2 \text { and } n=1,2, \ldots, N
\end{gathered}
$$

The subscript $j$ of the expectation operator denotes that the expectation is based on trader $j$ 's belief. Liquidity traders in market $n$ submit a random quantity $\tilde{z}_{n}$, and their trading across markets, $\tilde{z}_{n}$ 's, are independently and identically distributed. Competitive market makers (also called trader 0) observe the order imbalance $\tilde{y}_{n}=\tilde{q}_{1, n}+\tilde{q}_{2, n}+\tilde{z}_{n}$ and then clear the market by setting the asset price $p_{n}$ equal to the conditional expectation of the asset value $\tilde{v}_{n}$, given the observed order imbalance $\tilde{y}_{n}$ as follows:

$$
p_{n}=p\left(\tilde{y}_{n}\right)=E_{0}\left[\tilde{v}_{n} \mid \tilde{y}_{n}=\tilde{q}_{1, n}+\tilde{q}_{2, n}+\tilde{z}_{n}\right]
$$

The subscript 0 of the expectation operator denotes that the expectation is based on rational beliefs. Exogenous variables $\tilde{v}_{n}, \tilde{e}_{1, n}, \tilde{e}_{2, n}, \tilde{z}_{n}$ are independently and normally distributed with means zero and variances $\sigma_{v}^{2}, \sigma_{e}^{2}, \sigma_{e}^{2}, \sigma_{z}^{2}$, respectively. The quality of the private signals may be measured (inversely) by the noise-to-signal ratio $\theta \equiv \sigma_{e} / \sigma_{v}$. The amount of noise trading in each market may be measured by a normalized ratio $\phi \equiv \sigma_{z} / \sigma_{v}$. Kyle and Wang (1997) show that the one-shot model, given the type combination $\left(i_{n}, j_{n}\right)$, has a unique linear equilibrium $\left(q_{1, n}, q_{2, n}, p_{n}\right)$ as follows,

$$
\begin{gathered}
\tilde{q}_{1, n}=\gamma_{1, n} \tilde{s}_{1, n}=\frac{\left(1+2 K_{2}^{2} \theta^{2}\right)}{\lambda_{n} h}\left(\tilde{v}_{n}+\tilde{e}_{1, n}\right), \\
\tilde{q}_{2, n}=\gamma_{2, n} \tilde{s}_{2, n}=\frac{\left(1+2 K_{1}^{2} \theta^{2}\right)}{\lambda_{n} h}\left(\tilde{v}_{n}+\tilde{e}_{2, n}\right), \\
\tilde{p}_{n}=\lambda_{n} \tilde{y}_{n}=\frac{\gamma_{1, n}+\gamma_{2, n}}{\left(\gamma_{1, n}+\gamma_{2, n}\right)^{2}+\left(\gamma_{1, n}^{2}+\gamma_{2, n}^{2}\right) \theta^{2}+\phi^{2}}\left(\tilde{q}_{1, n}+\tilde{q}_{2, n}+\tilde{z}_{n}\right),
\end{gathered}
$$

where $h$ is a strictly positive constant, given $K_{1}, K_{2}$ and $\theta$.

The intensity parameters $\gamma_{1, n}$ and $\gamma_{2, n}$ and liquidity parameter $\lambda_{n}$ depend on the noise-to-signal ratio $\theta$, the noise trading ratio $\phi$, the misperception parameter $K$, and the type combination $\left(i_{n}, j_{n}\right)$ drawn at the beginning of the period. Moreover, for the same type combination $\left(i_{n}, j_{n}\right)=(i, j)$ the three parameters are uniquely determined, regardless of what $n$ is. Hence, without loss of generality, we may suppress the market index $n$ and write $\gamma_{1}(i, j), \gamma_{2}(i, j)$, and $\lambda(i, j)$ as the three parameters identical in those markets with the same type combination $(i, j)$. With the above equilibrium, the type-i trader's return, given a type- $j$ opponent in market 
$n$, denoted by $\tilde{R}_{n}(i, j)$, is obtained as follows:

$$
\begin{aligned}
\tilde{R}_{n}(i, j)= & \frac{\tilde{q}_{1, n}}{c_{0}}\left(\tilde{v}_{n}-\tilde{p}_{n}\right)=\frac{1}{c_{0}}\left\{\gamma_{1}(i, j)\left(\tilde{v}_{n}+\tilde{e}_{i, n}\right)\right. \\
& \left.\times\left[\tilde{v}_{n}-\lambda(i, j)\left(\gamma_{1}(i, j)\left(\tilde{v}_{n}+\tilde{e}_{1, n}\right)+\gamma_{2}(i, j)\left(\tilde{v}_{n}+\tilde{e}_{2, n}\right)+\tilde{z}_{n}\right)\right]\right\} .
\end{aligned}
$$

Note that in the last equality of (15) we substitute for $\tilde{q}_{1, n}$ and $\tilde{p}_{n}$ from Eq. (12)-(14).

The individual type- $i$ trader's return in market $n, \tilde{R}_{n}(i, j)$, is stochastic because the realization of the type combination $(i, j)$ in each market has a probability $x_{i}(t) x_{j}(t)$. Hence, we may identify the subsequence of those markets with the same realized type combination $(i, j)$ as $\left\{n_{k}\right\}_{k=1}^{N_{i, j}}$. In each market $n_{k}$, the individual type- $i$ trader's return, $\tilde{R}_{n_{k}}(i, j)$, is still stochastic because it depends on the exogenous random variables: $\tilde{v}_{n}, \tilde{e}_{1, n}, \tilde{e}_{2, n}$, and $\tilde{z}_{n}$. Note, however, that these exogenous variables are all independently and identically distributed across markets. As a result, the individual type- $i$ trader's returns in these markets, $\tilde{R}_{n_{k}}(i, j)$, are independently and identically distributed too. The average return of the type- $i$ traders facing type- $j$ opponents across these markets is given by $\bar{R}(i, j)=\sum_{k=1}^{N_{i, j}} b_{k}(i, j) \cdot \tilde{R}_{n_{k}}(i, j)$, where the weight $b_{k}(i, j)$ is the relative size of the type combination $(i, j)$ in market $n_{k}$ such that the weights across these markets sum to one, i.e., $\sum_{k=1}^{N_{i, j}} b_{k}(i, j)=1$. If the population share of each group in the economy is bounded below from zero, then the number of markets of each type combination $(i, j)$ becomes sufficiently large in a large economy, i.e., $\mathrm{N}_{i, j} \rightarrow \infty$, as $N \rightarrow \infty$. Moreover, in the large economy the average return of the type- $i$ traders across these markets converges to the expected return of a representative type- $i$ trader in these markets, denoted by $E[\tilde{R}(i, j)]$. I.e., as $N \rightarrow \infty$,

$$
\begin{aligned}
\bar{R}(i, j) & =\sum_{k=1}^{N_{i, j}} b_{k}(i, j) \cdot \tilde{R}_{n_{k}}(i, j) \rightarrow E[\tilde{R}(i, j)] \\
& =\frac{\sigma_{v}^{2}}{c_{0}} \gamma_{1}(i, j)\left(1-\lambda(i, j)\left(\gamma_{1}(i, j)+\gamma_{2}(i, j)\right)-\lambda(i, j) \gamma_{1}(i, j) \theta^{2}\right) .
\end{aligned}
$$

Note that the last equality in (16) is obtained by taking expectations on both sides of Eq. (15). For simplicity, we omit the subscript 0 for the expectation operator, but it should be understood that the expectation is based on the correct distributions, i.e., rational beliefs. In addition, we drop the market index $n_{k}$ when we write the expected return, $E[\tilde{R}(i, j)]$, because the individual returns $\tilde{R}_{n_{k}}(i, j)$ for all $n_{k}$ are independently and identically distributed across these markets. Equation (16) highlights the strategic nature of the pairwise contest between the two randomly matched informed traders since each trader's expected return depends also on the other trader's type.

The average return of the type- $i$ traders across all markets in the economy, $\bar{R}_{i}(x(t))$, is given by $\bar{R}_{i}(x(t))=\frac{b(i, 1)}{b(i, 1)+b(i, 2)} \cdot \bar{R}(i, 1)+\frac{b(i, 2)}{b(i, 1)+b(i, 2)} \cdot \bar{R}(i, 2)$, where 
the weight $b(i, j)$ is the relative size of the type combination $(i, j)$ in the economy such that the weights sum to one, i.e., $\sum_{i=1}^{2} \sum_{j=1}^{2} b(i, j)=1$. In the large economy, the relative size of each type-combination approaches the corresponding population distribution, i.e., $b(i, j) \rightarrow x_{i}(t) \cdot x_{j}(t)$. As a result, the average return of the type- $i$ traders converges to the expected return of the representative type- $i$ trader, $E\left[\tilde{R}_{i}(x(t))\right]$, in the large economy. I.e., as $N \rightarrow \infty$,

$$
\begin{aligned}
\bar{R}_{i}(x(t)) & =\frac{b(i, 1)}{b(i, 1)+b(i, 2)} \cdot \bar{R}(i, 1)+\frac{b(i, 2)}{b(i, 1)+b(i, 2)} \cdot \bar{R}(i, 2) \\
& \rightarrow x_{1}(t) \cdot E[\tilde{R}(i, 1)]+x_{2}(t) \cdot E[\tilde{R}(i, 2)]=E\left[\tilde{R}_{i}(x(t))\right] .
\end{aligned}
$$

Applying the payoff function, i.e., the expected return, in (17) to the general population dynamic in (9) yields the specific population dynamic for type- 2 traders in the pairwise contest as follows:

$$
\begin{aligned}
\dot{x}_{2}(t) & =x_{2}(t)\left(1-x_{2}(t)\right)\left(E\left[\tilde{R}_{2}(x(t))\right]-E\left[\tilde{R}_{1}(x(t))\right]\right) \\
& =x_{2}(t)\left(1-x_{2}(t)\right)\left(\left(a_{1}+a_{2}\right) x_{2}(t)-a_{1}\right),
\end{aligned}
$$

where $a_{1} \equiv E[\tilde{R}(1,1)]-E[\tilde{R}(2,1)], a_{2} \equiv E[\tilde{R}(2,2)]-E[\tilde{R}(1,2)]$.

The population dynamic in (18) depends crucially on the two return parameters, $a_{1}$ and $a_{2}$, where $a_{1}$ represents the expected return differential between a type- 1 trader and a type- 2 trader, both having a type- 1 opponent; $a_{2}$ represents the expected return differential between a type- 2 trader and a type- 1 trader, both having a type-2 opponent. We may partition the population dynamic (18) into four mutually exclusive categories, depending on the two return parameters: (I) $a_{1}>0, a_{2}<0$, (II) $a_{1}<0, a_{2}>0$, (III) $a_{1}>0, a_{2}>0$, and (IV) $a_{1}<0, a_{2}<0$. Following the standard analysis of the dynamic equilibrium in the corresponding evolutionary game, we obtain the asymptotically stable equilibria for each category. The results are shown in Theorem 1 below:

THEOREM 1. In our dynamic pairwise contest between rational and nonrational informed traders, the resulting population dynamic is given in (18). The long-run equilibria of the dynamic have four categories, depending on the signs of the return parameters $a_{1}$ and $a_{2}$, defined in (18):

(I) If one always earns a higher expected return by adopting a rational strategy than by adopting a nonrational strategy, regardless of his or her opponent's type, then rational traders as a group will dominate the economy in the long run.

(II) If one always earns a higher expected return by adopting a nonrational strategy than by adopting a rational strategy, regardless of his or her opponent's type, then nonrational traders as a group will dominate the economy in the long run. 
(III) If one always earns a higher expected return by adopting the same strategy as his or her opponent's type, then rational (nonrational) traders as a group will dominate the economy in the long run when the initial population share of the nonrational traders, $x_{2}(0)$, is below (above) the threshold level $a_{1} /\left(a_{1}+a_{2}\right)$.

(IV) If one always earns a higher expected return by adopting the opposite strategy of his or her opponent's type, then both rational and nonrational traders will survive in the long run such that their population share distribution approaches the unique asymptotically stable equilibrium: $\left(a_{2} /\left(a_{1}+a_{2}\right), a_{1} /\left(a_{1}+a_{2}\right)\right)$.

Figure 1 illustrates the evolution of the population share of the nonrational traders as a group according to Theorem 1 . The theorem indicates that nonrational traders dominate in category II, they may dominate in category III if their initial population share is greater than $a_{1} /\left(a_{1}+a_{2}\right)$, and they survive in category IV. But, Theorem 1 does not show whether the nonrational traders in these categories include both overconfident and underconfident traders, only one kind, or even none if the categories are in fact nonexistent in the model. Note, however, the theorem does show that these results depend on the signs of the two return parameters $a_{1}$ and $a_{2}$. It turns out that the signs depend only on two key parameters of the model: the noise-to-signal ratio $\theta$ (an inverse measure of the quality of the private signals)
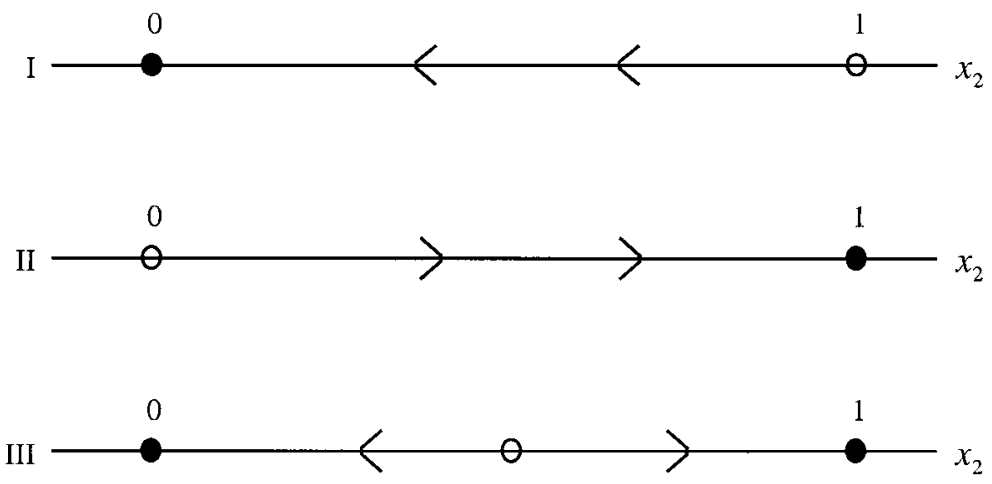

$$
\frac{a_{1}}{a_{1}+a_{2}}
$$

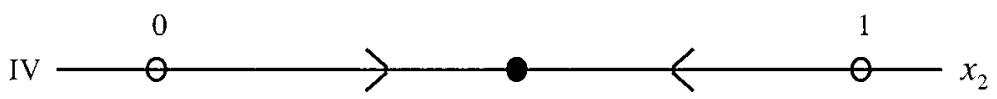

FIG. 1. The population dynamic under the pairwise contest.

(I) $\lim _{t \rightarrow \infty} x(t)=(1,0)$ is the unique asymptotically stable equilibrium.

(II) $\lim _{t \rightarrow \infty} x(t)=(0,1)$ is the unique asymptotically stable equilibrium.

(III) $\lim _{t \rightarrow \infty} x(t)=(1,0)$ if $x_{2}(0) \in\left[0, \frac{a_{1}}{a_{1}+a_{2}}\right) ;(0,1)$ if $x_{2}(0) \in\left(\frac{a_{1}}{a_{1}+a_{2}}, 1\right]$.

(IV) $\lim _{t \rightarrow \infty} x(t)=\left(\frac{a_{2}}{a_{1}+a_{2}}, \frac{a_{1}}{a_{1}+a_{2}}\right)$ is the unique asymptotically stable equilibrium.

$x_{2}$ is the population share of the group of type-2 (i.e., nonrational) traders. 
and the misperception parameter $K$ (an inverse measure of the confidence level of traders.) Recall that an informed trader is overconfident if $0 \leq K<1$, underconfident if $K>1$, and rational if $K=1$. We can identify the set of the two parameters $\theta$ and $K$ in $R_{+}^{2}$ that gives rise to each category such that $\mathrm{I}=\left\{(\theta, K) \in R_{+}^{2} \mid a_{1}>\right.$ $\left.0, a_{2}<0\right\}, \mathrm{II}=\left\{(\theta, K) \in R_{+}^{2} \mid a_{1}<0, a_{2}>0\right\}$, etc. The result is illustrated in Fig. 2 where the $\theta-K$ space is normalized into $X-Y$ space so that the entire universe $R_{+}^{2}$ can be shown equivalently in the finite space [0,2] $\times[0,2]$.

Several observations about Fig. 2 are in order. First, underconfident traders can never survive in the long run since the entire parameter space for underconfident trading, i.e., $K>1$, belongs to category I. In this category, rational traders always dominate. Second, the survivability of overconfident traders rises with the quality of their private signals and falls with the degree of overconfidence. For example, the figure shows that if the quality of the private signals is sufficiently high, i.e.,

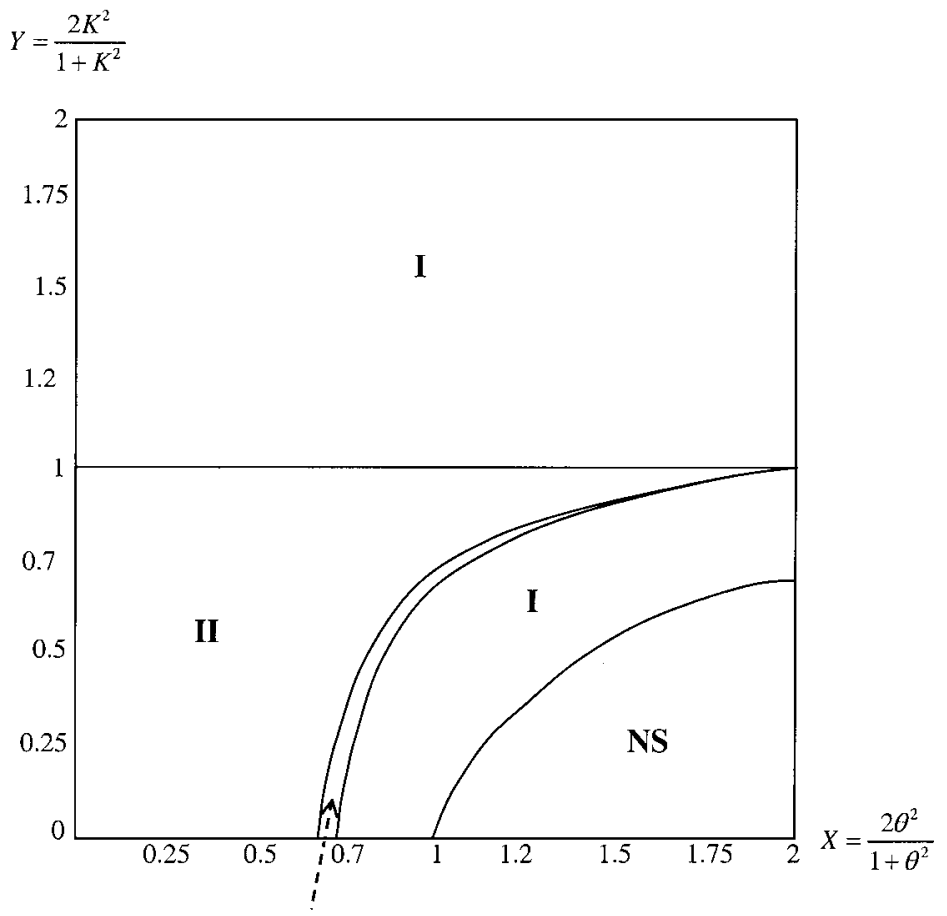

III

FIG. 2. The categories of the equilibria under the pairwise contest.

(I) Rational traders dominate nonrational traders in the long run.

(II) Nonrational traders dominate rational traders in the long run.

(III) Nonrational traders dominate if their wealth share is large enough; otherwise, rational traders dominate in the long run.

* The region NS corresponds to the case where the equilibrium of the one-shot model does not exist. 
$\theta$ is sufficiently small, overconfident traders, i.e., $K<1$, always dominate in category II. One may regard the ex-ante variance of the risky asset value, $\sigma_{v}^{2}$, as the fundamental risk in the economy. Holding forecast error $\sigma_{e}^{2}$ constant, then a small $\theta=\sigma_{e} / \sigma_{v}$ implies large fundamental risk, $\sigma_{v}^{2}$. In this context, overconfident traders tend to dominate the market when the fundamental risk is large. On the other hand, if the quality of the signals is relatively poor, i.e., $\theta$ is large, then overconfident traders can dominate only if their degree of overconfidence is modest, i.e., $K$ is not too small. This result is similar to Hirshleifer and Luo (2001). This similarity is remarkable because while fundamental risk is priced in Hirshleifer and Luo with risk-averse traders, the risk is not priced in our model under risk-neutrality.

In category III, the outcome depends on the initial population share distribution, $x(t)$, and this category comprises only a small subset of the parameter space $R_{+}^{2}$. Category IV, where both types of traders survive and coexist, is an empty set. Following Kyle and Wang (1997), region NS in the figure corresponds to the case where the one-shot model does not have equilibrium. Therefore, for all the parameter space where the equilibrium does exist, given a confidence parameter $K$, Fig. 2 implies that either rational or overconfident traders will dominate in the long run. However, if nonrational traders' confidence level, $K$, changes from time to time due to some exogenous, e.g., psychological, factors, then Fig. 1 suggests that the competitive advantage of a certain type may shift accordingly over time. For example, if nonrational traders' sentiment suddenly shifts from underconfidence to overconfidence, then rational traders tend to lose their competitive advantage to the newly minted overconfident opponents, as the long-run equilibrium now changes from category I to II, etc.

The dominance of overconfident traders over their rational opponents depends on two factors. First, overconfidence acts like a commitment device to aggressive trading, which makes their rational opponents less aggressive (Kyle and Wang (1997)). Second, given the private signals, informed traders' demands are positively correlated with the risky asset's value. These two factors together imply that, in comparison to rational traders, overconfident traders tend to buy more of the risky asset when their private signals indicate a positive prospect and sell more when the signals suggest the opposite. As a result, the demand differential between the overconfident traders and their rational opponents tends to be positively correlated with the asset's value. Such a positive correlation leads to a positive expected return differential between overconfident and rational traders, i.e., $E\left[\tilde{R}_{2}(x(t))\right)-$ $E\left(\tilde{R}_{1}(x(t))\right]>0$, despite the fact that the model assumes risk neutrality. To see this, using (3) the expected return differential can be expanded as follows:

$$
\begin{aligned}
E\left[R_{2}(x(t))\right]-E\left[R_{1}(x(t))\right]= & E\left[\left(\tilde{\alpha}_{2, n}(x(t))-\tilde{\alpha}_{1, n}(x(t))\right)\left(\tilde{r}_{n}-r\right)\right] \\
= & E\left[\tilde{\alpha}_{2, n}(x(t))-\tilde{\alpha}_{1, n}(x(t))\right]\left(E\left[\tilde{r}_{n}\right]-r\right) \\
& +\operatorname{Cov}\left[\tilde{\alpha}_{2, n}(x(t))-\tilde{\alpha}_{1, n}(x(t)), \tilde{r}_{n}\right] \\
= & \operatorname{Cov}\left[\tilde{\alpha}_{2, n}(x(t))-\tilde{\alpha}_{1, n}(x(t)), \tilde{r}_{n}\right] .
\end{aligned}
$$


Although there is no risk premium under risk neutrality, i.e., $E\left[\tilde{r}_{n}\right]-r=0$, the expected return differential is positive when the demand differential is positively correlated with the risky asset's value, i.e., $\operatorname{Cov}\left[\tilde{\alpha}_{2, n}(x(t))-\tilde{\alpha}_{1, n}(x(t)), \tilde{r}_{n}\right]>0$. As a result, the population share of the overconfident traders increases in the evolutionary process.

\section{INVESTOR SENTIMENT IN A PLAYING-THE-FIELD CONTEST}

In this section, we consider noise traders without market power in a playingthe-field contest. Consider a large economy with one riskless asset and $N$ risky assets. The riskless asset is in perfectly elastic supply and pays a fixed dividend $r$. The price of the riskless asset is normalized at one and hence the dividend $r$ is also the risk-free rate. The risky asset $n(n=1,2, \ldots, N)$ yields an uncertain dividends $\tilde{\varepsilon}_{t, n}$ at the end of each period $t$, but its supply is fixed and normalized at one. Assume that the dividends $\tilde{\varepsilon}_{t, n}$ across time and markets are independently and identically distributed with normal mean $r$ and variance $\sigma_{\varepsilon}^{2}$. While the risky asset's expected dividend payment $r$ is the same as the riskless rate, the expected total investment returns of the two assets need not be the same. This is so because the risky asset's price depends on the demand in the market, while the riskless asset's price is fixed.

In each asset market $n(n=1,2, \ldots, N)$, there are many two-period-lived traders. The specific trading mechanism is based on the overlapping generations model of DSSW (1990) $)^{3}$. Traders of the young generation trade the risky asset $n$ at the market price $p_{t, n}$ and then liquidate their positions of the risky asset at the price $\tilde{p}_{t+1, n}$ next period when they become old. As a result, the young traders' demands for the risky asset $n$ depend on their beliefs about the distribution of the liquidation price next period. Given the identical, normal distributions of fundamental dividends $\tilde{\varepsilon}_{t, n}$ across markets, the liquidation prices $\tilde{p}_{t+1, n}$ across markets are normally distributed with identical mean $\eta_{t+1}$ and variance $\sigma_{p_{t+1}}^{2}$. In each market $n$, there are two types of traders, depending on their beliefs about the mean, $\eta_{t+1}$. Type-1 (rational) traders accurately perceive the mean of the liquidation prices $\tilde{p}_{t+1, n}$, i.e., $E_{t}^{1}\left[\tilde{p}_{t+1, n}\right]=\eta_{t+1}$, while type- 2 (noise) traders misperceive the mean $\eta_{t+1}$ by a normal random variable $\tilde{\rho}_{t, n}$, i.e., $E_{t}^{2}\left[\tilde{p}_{t+1}\right]=\eta_{t+1}+\tilde{\rho}_{t, n}$. Note that the superscript $i$ of the expectation operator indicates that the expectation is based on type- $i$ traders' beliefs. Following DSSW (1990), let investors' one-period-ahead expectations about the variance, $\sigma_{p_{t+1}}^{2}$, be equal to the variance in the current period, i.e., $E_{t}^{i}\left[\sigma_{p_{t+1}}^{2}\right]=\sigma_{p_{t}}^{2}$, for $i=1,2$. In addition, assume that the misperception variables $\tilde{\rho}_{t, n}$ across time and markets are independently and identically distributed with mean $\rho^{*}$ and variance $\sigma_{\rho}^{2}$ and that they are independent of the fundamental

${ }^{3}$ See Kyle (1985), Russell and Thaler (1985), Black (1986), De Long et al. (1989), Campbell and Kyle (1993), Barberis et al. (1998), and Wang (2000) for other noise trading (or investor sentiment) models. 
dividents $\tilde{\varepsilon}_{t, n}$. Note that the "noise trader risk" is greater if the variance of the misperception variable, $\sigma_{p}^{2}$, is greater. All traders have CARA utility with a coefficient of risk aversion $\gamma$. The representative type- $i$ trader in market $n$ chooses a quantity $q_{t, n}^{i}$ of the risky asset $n$ to maximize his or her expected utility, given the price $p_{t, n}$ and the initial capital $c_{0}$, as follows:

$$
\begin{gathered}
\operatorname{Max}_{q_{t, n}^{i}} E_{t}^{i}\left[U\left(\tilde{\omega}_{t+1, n}^{i}\right)\right]=E_{t}^{i}\left[-e^{-(2 \gamma) \tilde{\omega}_{t+1, n}^{i}}\right], \\
\text { where } \tilde{\omega}_{t+1, n}^{i}=c_{0}+q_{t, n}^{i}\left(\tilde{\varepsilon}_{t, n}+\tilde{p}_{t+1, n}-(1+r) p_{t, n}\right), \quad i=1,2 .
\end{gathered}
$$

Solving Eq. (20) yields the asset demand for each representative trader as follows:

$$
q_{t, n}^{1}=\frac{r+\eta_{t+1}-(1+r) p_{t, n}}{2 \gamma\left(\sigma_{p_{t}}^{2}+\sigma_{\varepsilon}^{2}\right)} ; \quad q_{t, n}^{2}=\frac{r+\eta_{t+1}+\rho_{t, n}-(1+r) p_{t, n}}{2 \gamma\left(\sigma_{p_{t}}^{2}+\sigma_{\varepsilon}^{2}\right)} .
$$

Equation (21) indicates that a bullish noise trader (i.e., $\rho_{t, n}>0$ ) holds more of the risky asset than a rational trader does, while a bearish noise trader (i.e., $\rho_{t, n}<0$ ) demands less. The market-clearing price is set such that the total demand for asset $n$ equals its total supply (which is normalized to one). Given that the measure of each type of trader in the market is identified with its population share, the market clearing condition is:

$$
q_{t, n}^{1}\left(1-x_{2}(t)\right)+q_{t, n}^{2} x_{2}(t)=1 .
$$

Plugging Eq. (21) into (22) and rearranging yields the equilibrium price $\tilde{p}_{t, n}$ as follows:

$$
\begin{gathered}
\tilde{p}_{t, n}=\frac{1}{1+r}\left[r+\eta_{t+1}-2 \gamma\left(\sigma_{p_{t}}^{2}+\sigma_{\varepsilon}^{2}\right)+x_{2}(t) \tilde{\rho}_{t, n}\right], \\
\text { where } \sigma_{p_{t}}^{2}=\frac{x_{2}^{2}(t) \sigma_{\rho}^{2}}{(1+r)^{2}} .
\end{gathered}
$$

Equation (23) shows that the equilibrium price $\tilde{p}_{t, n}$ in market $n$ depends crucially on the misperception variable $\tilde{\rho}_{t, n}$ in that market. Given that the misperception variables $\tilde{p}_{t, n}$ across markets are independently and identically distributed, so are the asset prices $\tilde{p}_{t, n}$ across markets. Furthermore, the investment return of the type- $i$ trader in market $n$, i.e., $\tilde{R}_{i, n}(x(t))$, is given by

$$
\tilde{R}_{i, n}(x(t))=\frac{q_{t, n}^{i}}{c_{0}}\left(\tilde{\varepsilon}_{t, n}+\tilde{p}_{t+1, n}-(1+r) \tilde{p}_{t, n}\right), \quad \text { for } i=1,2 ; \quad n=1,2, \ldots, N .
$$

Since the dividends $\tilde{\varepsilon}_{t, n}$ and the asset prices $\tilde{p}_{t, n}$ are both independently and identically distributed across markets, so are the investment returns $\tilde{R}_{i, n}(x(t))$ of the type- $i$ traders. The average return of the type- $i$ traders across markets, $\bar{R}_{i}(x(t))$, is given by $\bar{R}_{i}(x(t))=\sum_{n=1}^{N} b_{i, n} \tilde{R}_{i, n}(x(t))$, where the weight $b_{i, n}$ is the relative 
size of type- $i$ traders in market $n$ such that the weights across markets sum to one, i.e., $\sum_{n=1}^{N} b_{i, n}=1$. Given that the individual returns $\tilde{R}_{i, n}(x(t))$ are independently and identically distributed across markets, the average return converges to the expected investment return of the representative type- $i$ trader, i.e., $E\left(\tilde{R}_{i}(x(t))\right)$, in the large economy. I.e., as $N \rightarrow \infty$.

$$
\bar{R}_{i}(x(t))=\sum_{n=1}^{N} b_{i, n} \tilde{R}_{i, n}(x(t)) \rightarrow E\left[\tilde{R}_{i}(x(t))\right]=E\left[E_{t}\left[\tilde{R}_{i, n}(x(t)) \mid \tilde{\rho}_{t, n}\right]\right] .
$$

The last equality in Eq. (25) states that the unconditional expected return is the expected value of the conditional expected return, given the misperception variable $\tilde{\rho}_{t, n}$. Using Eqs. (21)-(24), it is straightforward to calculate the conditional expected return for each type of trader as follows:

$$
\begin{gathered}
E_{t}\left[\tilde{R}_{1, n}(x(t)) \mid \tilde{\rho}_{t, n}\right]=\frac{q_{t, n}^{1}}{c_{0}}\left(r+\eta_{t+1}-(1+r) p_{t, n}\right) \\
=\frac{\left(2 \gamma\left(\sigma_{p_{t}}^{2}+\sigma_{\varepsilon}^{2}\right)-x_{2}(t) \tilde{\rho}_{t, n}\right)^{2}}{2 \gamma\left(\sigma_{p_{t}}^{2}+\sigma_{\varepsilon}^{2}\right) c_{0}} \\
E_{t}\left[\tilde{R}_{2, n}(x(t)) \mid \tilde{\rho}_{t, n}\right] \\
=\frac{\left(2 \gamma\left(\sigma_{p_{t}}^{2}+\sigma_{\varepsilon}^{2}\right)-x_{2}(t) \tilde{\rho}_{t, n}\right)\left(2 \gamma\left(\sigma_{p_{t}}^{2}+\sigma_{\varepsilon}^{2}\right)+\left(1-x_{2}(t)\right) \tilde{\rho}_{t, n}\right)}{2 \gamma\left(\sigma_{p_{t}}^{2}+\sigma_{\varepsilon}^{2}\right) c_{0}} .
\end{gathered}
$$

Given (26) and (27), the unconditional expected return differential between the representative type- 2 trader and the representative type- 1 trader in the economy, i.e., $E\left[\tilde{R}_{2}(x(t))\right]-E\left[\tilde{R}_{1}(x(t))\right]$, is obtained as follows:

$$
\begin{aligned}
E\left[\tilde{R}_{2}(x(t))\right]-E\left[\tilde{R}_{1}(x(t))\right] & =E\left[E_{t}\left[\tilde{R}_{2, n}(x(t)) \mid \rho_{t, n}\right]-E_{t}\left[\tilde{R}_{1, n}(x(t)) \mid \rho_{t, n}\right]\right] \\
& =E\left[\frac{1}{c_{0}}\left(\tilde{\rho}_{t, n}-\frac{x_{2}(t) \tilde{\rho}_{t, n}^{2}}{2 \gamma\left(\sigma_{p_{t}}^{2}+\sigma_{\varepsilon}^{2}\right)}\right)\right] \\
& =\frac{1}{c_{0}}\left(\rho^{*}-\frac{\rho^{* 2}+\sigma_{\rho}^{2}}{2 \gamma\left(\frac{x_{2}(t) \sigma_{\rho}^{2}}{(1+r)^{2}}+\frac{\sigma_{\varepsilon}^{2}}{x_{2}(t)}\right)}\right)
\end{aligned}
$$

Applying Eq. (28) to the general population dynamic in (9) yields the specific population dynamic for the playing-the-field contest (without loss of generality, show the population share for type- 2 trader):

$$
\begin{aligned}
\dot{x}_{2}(t) & =x_{2}(t)\left(1-x_{2}(t)\right)\left(E\left[\tilde{R}_{2}(x(t))\right]-E\left[\tilde{R}_{1}(x(t))\right]\right) \\
& =\frac{1}{c_{0}} x_{2}(t)\left(1-x_{2}(t)\right)\left(\rho^{*}-\frac{\rho^{* 2}+\sigma_{\rho}^{2}}{2 \gamma\left(\frac{x_{2}(t) \sigma_{\rho}^{2}}{(1+r)^{2}}+\frac{\sigma_{\varepsilon}^{2}}{x_{2}(t)}\right)}\right) .
\end{aligned}
$$


Given the population dynamic in (29), we examine its dynamic equilibrium following the standard analysis in the corresponding evolutionary game. In doing so, we consider first the special case without fundamental risk, i.e., $\sigma_{\varepsilon}^{2}=0$, and then the general case with fundamental risk, i.e., $\sigma_{\varepsilon}^{2} \neq 0$, respectively.

\section{A. Dynamic Playing-The-Field Contest without Fundamental Risk}

If there is no fundamental risk, i.e., $\sigma_{\varepsilon}^{2}=0$, then the population dynamic for the playing-the-field contest reduces to the following:

$$
\begin{aligned}
\dot{x}_{2}(t) & =x_{2}(t)\left(1-x_{2}(t)\right)\left(E\left[\tilde{R}_{2}(x(t))\right]-E\left[\tilde{R}_{1}(x(t))\right]\right) \\
& =\frac{1}{c_{0}} x_{2}(t)\left(1-x_{2}(t)\right)\left(\rho^{*}-\frac{(1+r)^{2}\left(\rho^{* 2}+\sigma_{\rho}^{2}\right)}{2 \gamma \sigma_{\rho}^{2} x_{2}(t)}\right) .
\end{aligned}
$$

Solving $\dot{x}_{2}(t)=0$ yields the steady states of the population dynamic in (30). The states $x_{2}=0$ and $x_{2}=1$ are always stationary in the dynamic. If noise traders on average have negative sentiment, i.e., $\rho^{*}<0$, then the expected return differential is negative for all $x(t)$. This means that starting from any nonstationary states $x(t) \notin$ $\{(1,0),(0,1)\}$, the population share of the noise traders will decline to zero in the long run. On the other hand, if noise traders on average have positive sentiment, i.e., $\rho^{*}>0$, then for some parameter values the expected return differential is also negative. In this case, the population share of the noise traders will also decline to zero in the long run. In addition, there may be one interior steady state, $x_{2}=\mu$, where $\mu$ is given by $\mu=\left((1+r)^{2}\left(\rho^{* 2}+\sigma_{\rho}^{2}\right)\right) / 2 \gamma \rho^{*} \sigma_{\rho}^{2}$. Interestingly, it turns out that the interior steady state is unstable and the long run equilibrium depends on the current population state relative to the interior steady state. To see this, note that if the current noise trader share is below the interior steady state, i.e., $x_{2}(t)<\mu$, then the expected return differential is always negative and, as a result, the population share of the noise traders will decline to zero in the long run. On the other hand, if the current noise trader share is above the interior steady state, i.e., $x_{2}(t)>\mu$, then the expected return differential is always positive and the population share of the noise traders will increase to one. Such a dichotomy of long-run equilibria implies that the unique interior steady state itself is asymptotically unstable. Theorem 2.1 summarizes the dynamic equilibrium result as follows:

THEOREM 2.1. In our dynamic playing-the-field contest without fundamental risk, the resulting population dynamic is given in (30). Given the interior steady state $\mu$, the equilibria of the dynamic have three categories depending on the average sentiment $\rho^{*}$ and the noise trader risk $\sigma_{\rho}^{2}$.

(I) If noise traders on average have negative sentiment $\left(\rho^{*}<0\right)$, then rational traders as a group will dominate the economy in the long run.

(II) If noise trader risk is small or if average investor sentiment is positive but not moderate, then rational traders as a group will dominate the economy in the long run. 
(III) If noise trader risk is large and if average investor sentiment is moderate, then rational (nonrational) traders as a group will dominate the economy in the long run when the initial population share of the nonrational traders, $x_{2}(0)$, is below (above) the threshold level $\mu$.

Figure 3 illustrates the evolution of the population share of the noise traders as a group according to Theorem 2.1 under each of the three categories. The intuition of Theorem 2.1 is as follows. In category I, noise traders with a negative average sentiment, $\rho^{*}<0$, tend to hold less of the undervalued risky asset and, as a result, lose money to the rational traders who hold more of the risky asset. In category II with positive average sentiment, $\rho^{*}>0$, consider an extreme case where the noise trader risk is negligible relative to the average sentiment such that $\frac{\sigma_{\rho}}{\rho^{*}} \rightarrow 0$. In this special case with neither fundamental risk nor, effectively, noise trader risk, the noise traders who overestimate the expected future price of the risky asset will trade extremely large quantity and, as a result, lose arbitrarily large profits in trading against rational traders with unlimited arbitrage.

Category III corresponds to the case where noise traders have positive sentiment and the noise trader risk, $\sigma_{\rho}^{2}$, is relatively large. With a positive sentiment, noise traders tend to hold more of the risky asset and consequently push up the price of the risky asset (see Eq. (23).) On the other hand, the large noise trader risk tends to trim noise traders' aggressive trading and hence eliminate some of the price
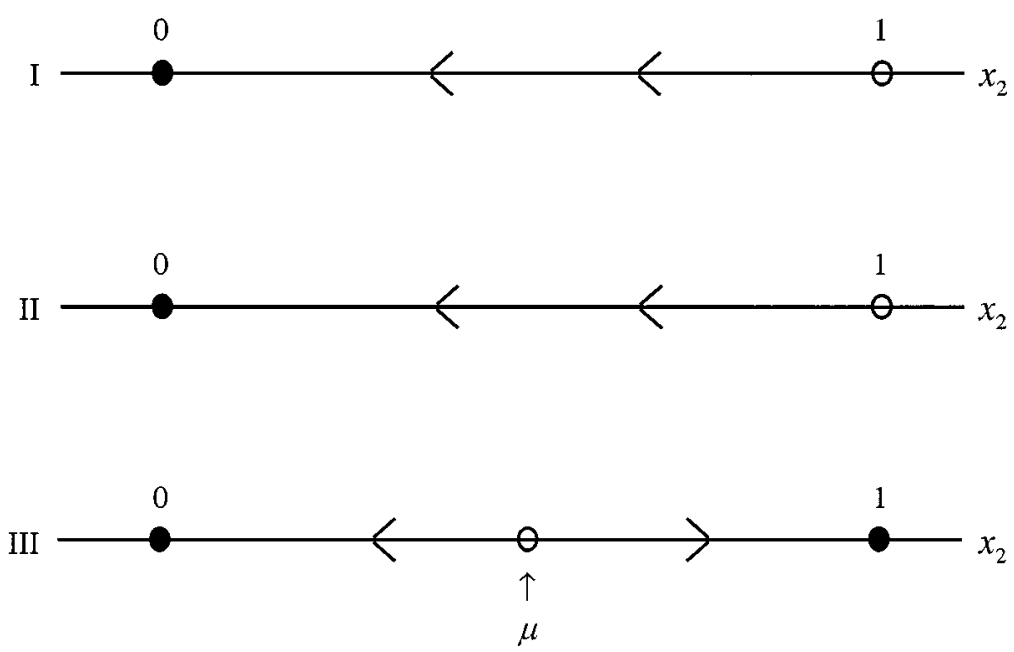

FIG. 3. The population dynamic under the playing-the-field contest without fundamental risk.

(I) $\lim _{t \rightarrow \infty} x(t)=(1,0)$ is the unique asymptotically stable equilibrium.

(II) $\lim _{t \rightarrow \infty} x(t)=(1,0)$ is the unique asymptotically stable equilibrium.

(III) $\lim _{t \rightarrow \infty} x(t)=\left\{\begin{array}{l}(1,0) \text { if } x_{2}(0) \in[0, \mu) \\ (0,1) \text { if } x_{2}(0) \in(\mu, 1]\end{array}\right.$ 
pressure. Such a price reduction effect increases with the presence of noise traders (see Eq. (23).) Therefore, if the presence of the noise traders is large enough, i.e., $x_{2}(t)>\mu$, then the noise traders' moderately aggressive trading will generate greater returns than the rational traders do. On the other hand, if the presence of the noise traders is not large enough, i.e., $x_{2}(t)<\mu$, then rational traders are more willing to bet against the noise traders' misperception and, as a result, exploit profits from it. Note that DSSW's (1990) long run dynamic without fundamental risk is essentially the same as our category III, while our categories I and II are absent.

\section{B. Dynamic Playing-The-Field Contest with Fundamental Risk}

In this section, we analyze the dynamic equilibrium under the general case with fundamental risk, i.e., $\sigma_{\varepsilon}^{2} \neq 0$. Solving $\dot{x}_{2}(t)=0$ for the population dynamic in (29) yields the steady states of the population dynamic. The states $x_{2}=0$ and $x_{2}=1$ are always stationary in the dynamic. The long run equilibria of the population dynamic depend critically on the expected return differential in (29). If noise traders have negative average sentiment, i.e., $\rho^{*}<0$, then the expected return differential is negative for all $x(t)$. This means that starting from any nonstationary states the population share of the noise traders will decline to zero in the long run. On the other hand, if noise traders have positive average sentiment in the economy, i.e., $\rho^{*}>0$, then for some parameter values the expected return differential is positive for all $x(t)$. In this case, starting from any nonstationary states the population share of the noise traders will increase to one in the long run. The third possibility is that for some parameter values the expected return differential is zero. In this case, the dynamic may have at most two interior steady states, denoted by $\mu_{L}$ and $\mu_{H}$, respectively, as follows,

$$
\begin{aligned}
& \mu_{L}=\frac{(1+r)^{2}\left(\sigma_{\rho}^{2}+\rho^{* 2}\right)-(1+r) \sqrt{(1+r)^{2}\left(\sigma_{\rho}^{2}+\rho^{* 2}\right)^{2}-16 \gamma^{2} \sigma_{\rho}^{2} \sigma_{\varepsilon}^{2} \rho^{* 2}}}{4 \gamma \sigma_{\rho}^{2} \rho^{*}}, \\
& \mu_{H}=\frac{(1+r)^{2}\left(\sigma_{\rho}^{2}+\rho^{* 2}\right)+(1+r) \sqrt{(1+r)^{2}\left(\sigma_{\rho}^{2}+\rho^{* 2}\right)^{2}-16 \gamma^{2} \sigma_{\rho}^{2} \sigma_{\varepsilon}^{2} \rho^{* 2}}}{4 \gamma \sigma_{\rho}^{2} \rho^{*}},
\end{aligned}
$$

provided that the expression inside the square roots in (31) and (32) is nonnegative. Following the standard analysis of the dynamic equilibrium in the corresponding evolutionary game (see the Appendix for detail), we obtain the asymptotically stable equilibria for the dynamic in (29) as shown in Theorem 2.2. below:

THEOREM 2.2. In our dynamic playing-the-field contest with fundamental risk, the resulting population dynamic is given in (29). Given the two interior steady states $\mu_{L}$ and $\mu_{H}$ from (31) and (32), respectively, the long run equilibria of the dynamic have four categories. 
(I) If noise traders on average have negative sentiment, then rational traders as a group will dominate the economy in the long run.

(II) If noise traders on average have positive sentiment and they always earns higher expected returns than do the rational traders, regardless of the current population share distribution, then the noise traders as a group will dominate the economy in the long run.

(III) If noise traders on average have positive sentiment and there exists a unique interior steady state, $\left(1-\mu_{L}, \mu_{L}\right)$, then both rational and noise traders will survive in the long run such that their population share distribution approaches the unique interior steady state.

(IV) If noise traders on average have positive sentiment and there exist two interior steady states, $\left(1-\mu_{L}, \mu_{L}\right)$ and $\left(1-\mu_{H}, \mu_{H}\right)$, then there are two possibilities, depending on the initial population share of the noise traders, $x_{2}(0)$.

(i) If the noise traders' initial population share is below $\mu_{H}$, then both rational and noise traders will survive such that the population share distribution approaches the lower interior steady state: $\left(1-\mu_{L}, \mu_{L}\right)$.

(ii) If the noise traders' initial population share is above $\mu_{H}$, then the noise traders as a group will dominate the economy in the long run.

Figure 4 illustrates the evolution of the population share of the noise traders as a group according to Theorem 2.2. The theorem suggests that noise traders vanish in the long run if their average sentiment is bearish, i.e., $\rho^{*}<0$ (category I); otherwise, they always survive under positive sentiment, i.e., $\rho^{*}>0$. Furthermore, noise traders dominate the markets if they always earn higher expected returns than do rational traders, i.e., $E\left[\tilde{R}_{2}(x(t))\right]-E\left[\tilde{R}_{1}(x(t))\right]>0$ (category II). In category III, starting from any nonstationary states, i.e., $x(t) \notin\{(1,0),(0,1)\}$, the population share distribution will converge to the unique asymptotically stable interior equilibrium, $\left(1-\mu_{L}, \mu_{L}\right)$, where both rational and noise traders survive in the long run. Category IV has two interior steady states. Noise traders dominate if their initial population share is greater than the higher interior state $\mu_{H}$; otherwise, they survive along with rational traders in the long run as the population share distribution converges to the unique asymptotically stable interior equilibrium, $\left(1-\mu_{L}, \mu_{L}\right)$. DSSW (1990) obtain similar results regarding the survival of noise traders based on an imitation process where the wealth of trader is held fixed. In fact, DSSW's long run dynamic with fundamental risk is essentially the same as category IV, while the results for other categories are absent. Therefore, our finding in Theorem 2.2 extends DSSW (1990) by showing that the survival of noise traders is justified even if the wealth accumulation process is endogenously determined.

Theorem 2.2 shows that the categorization depends on the average sentiment parameter, $\rho^{*}$, and the values of the two interior states, $\mu_{L}$ and $\mu_{H}$. Hence, we may determine the exogenous parameter space for each category according to the values of these parameters. The parameter space for category I is straightforward to obtain, since it consists of all cases with negative average sentiment, i.e., $\rho^{*}<0$. 

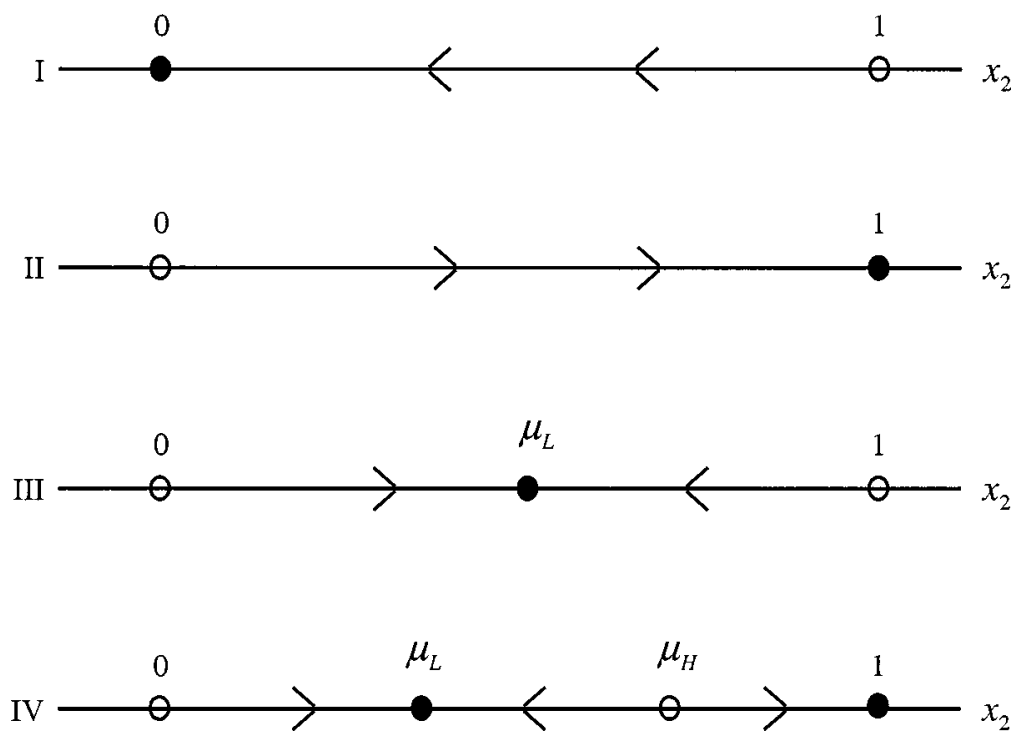

FIG. 4. The population dynamic under the playing-the-field contest with fundamental risk.

(I) $\lim _{t \rightarrow \infty} x(t)=(1,0)$ is the unique asymptotically stable equilibrium.

(II) $\lim _{t \rightarrow \infty} x(t)=(0,1)$ is the unique asymptotically stable equilibrium.

(III) $\lim _{t \rightarrow \infty} x(t)=\left(1-\mu_{L}, \mu_{L}\right)$ is the unique asymptotically stable equilibrium.

(IV) $\lim _{t \rightarrow \infty} x(t)= \begin{cases}\left(1-\mu_{L}, \mu_{L}\right) & \text { if } x_{2}(0) \in\left[0, \mu_{H}\right) \\ (0,1) & \text { if } x_{2}(0) \in\left(\mu_{H}, 1\right]\end{cases}$

$x_{2}$ is the population share of the group of type-2 (i.e., nonrational) traders.

But, obtaining the respective parameter spaces for categories II to IV is difficult. To simplify the matter, define a normalized measure of the average investor sentiment by $\varphi \equiv \rho^{*} / \sigma_{\rho}$, a ratio of the fundamental to noise trader risk by $\psi \equiv \sigma_{\varepsilon} / \sigma_{\rho}$ and a constant $\zeta \equiv 4 \gamma \rho^{*} /(1+r)$. Rewrite the expressions of the two interior states $\mu_{L}$ and $\mu_{H}$ in (31) and (32) as follows:

$$
\begin{gathered}
\mu_{L}=\frac{1+r}{\zeta}\left(1+\varphi^{2}-\sqrt{g}\right), \quad \mu_{H}=\frac{1+r}{\zeta}\left(1+\varphi^{2}+\sqrt{g}\right), \quad \text { and } \\
g=\left(1+\varphi^{2}\right)^{2}-\psi^{2} \zeta^{2} .
\end{gathered}
$$

Obviously, the two interior states $\mu_{L}$ and $\mu_{H}$ exist only if $g>0$. In order to focus on the effects of the average investor sentiment, $\varphi$, and the ratio of the fundamental to noise trader risk, $\psi$, fix the constant $\zeta=3$ and the risk-free rate $r=0.05$. We can identify the set of the two parameters $(\varphi, \psi)$ in $R_{+}^{2}$ that gives rise to each category, respectively, as II $=\left\{(\varphi, \psi) \in R_{+}^{2} \mid g<0\right.$, or $g>0$ and $\left.\mu_{L}>1\right\}$, III $=$ $\left\{(\varphi, \psi) \in R_{+}^{2} \mid g>0\right.$ and $\left.0<\mu_{L}<1<\mu_{H}\right\}$, and IV $=\left\{(\varphi, \psi) \in R_{+}^{2} \mid g>0\right.$ and $\left.0<\mu_{L}<\mu_{H}<1\right\}$. The result is illustrated in Fig. 5 where the $\psi-\varphi$ space 
$Y=\frac{2 \varphi^{2}}{1+\varphi^{2}}$

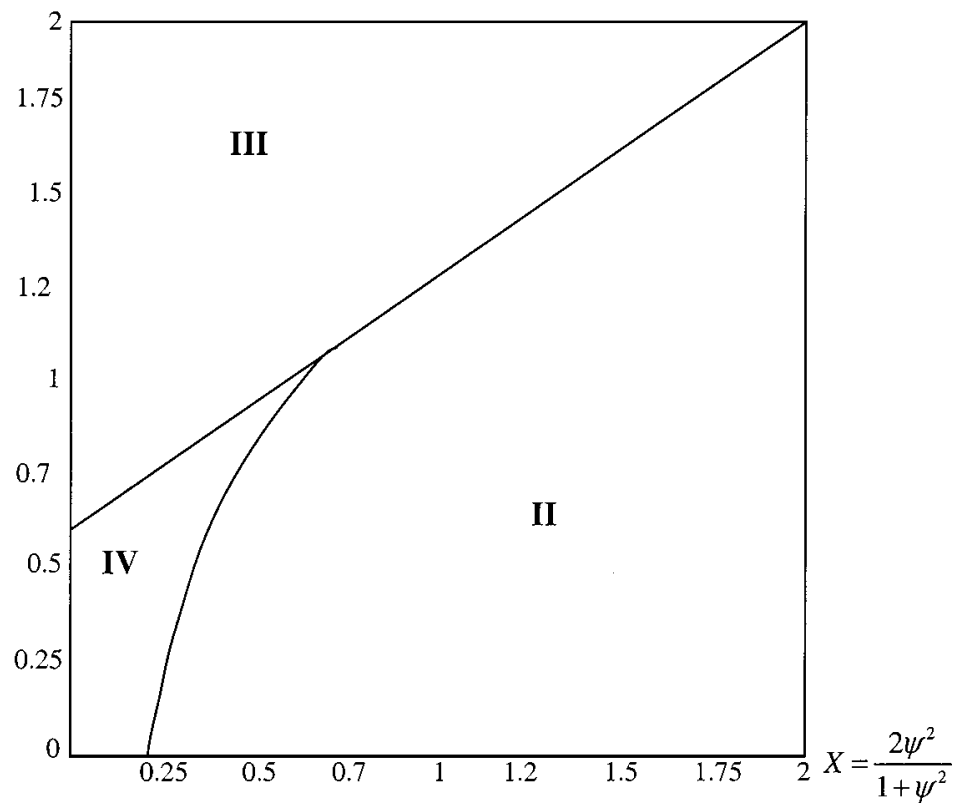

FIG. 5. The categories of the equilibria under positive sentiment.

(II) Nonrational traders dominate rational traders in the long run.

(III) Both rational and nonrational traders survive in the long run.

(IV) Nonrational traders dominate if their wealth share is large enough; otherwise, both types of traders survive in the long run.

* Category I corresponds to the case with negative sentiment (i.e., $Y<0$ ) and hence is not shown.

is normalized into $X-Y$ space so that the entire universe $R_{+}^{2}$ can be shown in the finite space $[0,2] \times[0,2]$.

Figure 5 suggests that bullish noise traders dominate the economy only when the fundamental risk is not too small relative to the noise trader risk, i.e., $\psi \equiv$ $\sigma_{\varepsilon} / \sigma_{\rho} \gg 0$, and their positive sentiment, $\varphi \equiv \rho^{*} / \sigma_{\rho}$, is not too extreme (category II). The intuition is as follows. A relatively large fundamental risk will deter rational traders' ability and willingness to trade against the mistake of noise traders. A modest positive sentiment allows noise traders to hold more of the risky asset without causing too much undesirable price impact. As a result, moderately bullish noise traders tend to generate higher expected returns than do the rational traders, particularly when the fundamental risk is large. This implies that in the large economy these modest noise traders as a group will accumulate wealth at a higher speed than will the rational traders. As a result, the noise traders will eventually dominate the market in the long run as their population share increases to one. 
On the other hand, if the fundamental risk is small relative to the noise trader risk and the positive sentiment is excessive, then the resulting adverse price impact may be large enough to cancel out the benefit of the positive sentiment. In this case, such bullish noise traders tend to survive but not dominate (category III). Last, if both the positive sentiment and the fundamental risk are small (category IV), then the noise traders as a group either dominate or survive in the long run, depending on their initial population share relative to the higher interior state, $\mu_{H}$, as described in Theorem 2.2.

\section{DISCUSSION OF ANALYSIS INCLUDING EMPIRICAL IMPLICATIONS}

In this section, we discuss the implications and generalization of our theoretical analysis. It is worth noting first that, unlike the usual biological population process, we do not obtain the population dynamic simply by assuming some fitness criterion, e.g., recent profits or expected utility, for the determination of the growth of each type of trader. Instead, following Blume and Easley (1992), we take the view that there is a natural population dynamic in asset markets that emerges from the process of wealth accumulation. In this process, the endogenously determined growth rate of wealth accumulation governs the relative fitness of each type of trader in the market. As a result, this dynamic does not depend on individual adaptation as required in the usual learning-imitation process. For example, both DSSW (1990) and Hirshleifer and Luo (2001) assume recent profitability to be the fitness criterion in their imitation processes, whereas Palomino (1996) assumes expected utility as the fitness criterion in his adopted imitation process. Thus, our endogenously determined group wealth accumulation process distinguishes our model from these other models.

The population dynamic in this paper depicts the growth of the wealth of the group, not of individual traders. In fact, the survival of the group of nonrational investors is, to some extent, at the expense of the individual investors. This happens because irrationality (overconfidence or investor sentiment) induces individual traders to trade more aggressively and, as a result, they have a higher expected return as well as a higher variance than rational traders do. This means that individual nonrational investors tend to have a higher probability of going bankrupt than do individual rational investors. In this sense, individual nonrational investors may be subject to the gambler's ruin problem (Samuelson $(1971,1977)$ ). In this paper, however, we show that in a large economy where the high variance risk is diversified in the group wealth portfolio, the resulting population dynamic is driven primarily by the expected return differential between the two groups. Therefore, the gambler's ruin problem at the individual level does not prevent the survival of nonrational investors as a group.

What happens then for a small economy where the high variance risk cannot be diversified away? In this case, there is a nonlinear (concave) relation between 
return and population growth. Palomino (1996) examines this case and finds that spiteful noise traders can hurt rational investors more than themselves. As a result, even with the high variance risk, the noise traders can still dominate the market if they are moderately over-optimistic and if the fundamental risk is relatively large. Remarkably, the condition for the survival of noise traders in a small economy is essentially the same as the condition obtained in our model under a large economy. This invariance result highlights that our main conclusion-moderately nonrational investors can dominate the market, particularly when the fundamental risk is large-is robust to a nonlinear (concave) relation between return and population growth.

Overconfidence acts like a commitment device to aggressive trading in our pairwise contest, but the commitment device effect does not require that overconfident traders move first. In fact, at the beginning of each contest a trader does not know which type of the other trader, rational or nonrational, he or she is going to face. There are four possible type combinations of the two traders and the probability of each combination is governed by the population distribution at that time. The duopoly model of Kyle and Wang (1997) does not require that overconfident traders move first either. In fact, Kyle and Wang show that if a rational trader moves first, then a moderately overconfident trader will not only outperform the first-move rational trader, but also do better than if he or she were also rational. On the other hand, if an overconfident trader moves first, then the second mover is better off being overconfident than being rational. This leads to a Nash equilibrium in which both traders are overconfident. This equilibrium is a prisoner's dilemma in which both traders make less profits than if they both were rational. This Nash equilibrium outcome generalizes the special case of a single overconfident insider as in Odean (1998).

In our evolutionary model once investors are born to be a certain type (rational or nonrational), they are "programmed" to their type in the evolutionary game. One might argue that overconfident investors should learn over time to change their erroneous belief and eventually converge to the rational belief. Empirical evidence in psychology literature (Kahneman et al. (1982)) shows that people do not update their beliefs rationally. For example, Daniel et al. (1998) consider an updating rule based on biased self-attribution - a rule by which investors essentially believe "heads I win, tails it's chance" (Langer and Roth (1975) and Gervais and Odean (2001)). In such a biased learning process, overconfident beliefs need not converge to rational beliefs.

The most interesting empirical implication of our analysis lies in the area of fund management. Under the view of the efficient market hypothesis, all assets are efficiently priced and hence it is optimal to invest passively in the index fund. One can view, therefore, these passive fund managers as the rational traders in the market. On the other hand, fund managers, who are overconfident about their private information or too optimistic about the future prospect of the asset value, tend to disagree with the market efficiency hypothesis and trade actively and aggressively in the market. In other words, these active fund managers tend to manifest 
themselves as the nonrational traders in the market. In this context, our analysis of the survival issue provides several new empirical implications for the survival of active fund management. First, although individual active fund managers trade more aggressively and hence die faster than individual passive fund managers, the active fund management style (i.e., the "group") can still persist in the market, e.g., Fidelity investment group versus Vanguard investment group.

Second, the group of active fund managers survives better in a market with high fundamental risk. This means that active fund management should be more popular in the market where the fundamental value of assets is more difficult to assess. This leads to several testable implications. For example, active fund management should be more popular in high-risk funds than in low-risk funds. Similarly, active fund management should be more popular in the stock market than in the bond market and more popular in emerging markets than in the U.S. market, etc. Finally, while individual active fund managers may display various degrees of overconfidence or investor sentiment, the surviving active fund managers should exhibit moderate aggressiveness, rather than extreme aggressiveness.

Although in this paper we focus on the survival of nonrational investors in asset markets, our key finding that moderately aggressive, nonrational agents can enhance their survivability seems to have broader applications in other economic settings. For example, Bernardo and Welch (2000) examine a model of informational cascades and find that overconfident entrepreneurs, who overweigh their private information, can better convey valuable information to the group and hence avoid the bad herding equilibrium. Goel and Thakor (2000) consider a model of leadership and show that the overconfident manager, who understimates his or her project risk, has a greater chance to be chosen as the leader (CEO) than an otherwise identical rational manager. This is so because the race to CEO is like a winner-take-all game, in which only the extreme positive performance will be awarded.

\section{CONCLUSION}

We examine the long run survival of nonrational traders in a dynamic, evolutionary model. Specifically, we develop a general population dynamic for a large economy with rational and nonrational traders according to the process of wealth accumulation in asset markets. The dynamic indicates that the growth rate of wealth accumulation drives the evolutionary process in asset markets. This endogenously determined group wealth accumulation process distinguishes our evolutionary model from the previous models with exogenous imitation processes.

We apply our population dynamic to examine the survival of overconfident traders in a pairwise contest and the survival of noise traders in a playing-the-field contest. We find that neither underconfident nor bearish sentiment can survive. On the other hand, investors with moderate overconfidence or bullish sentiment can survive in the long run. Furthermore, these moderately aggressive investors may dominate the market if fundamental risk in the market is sufficiently large. These findings provide interesting new empirical implications for the survivability 
of active fund management. Overall, our results lend support to the relevance of the psychology of investors with respect to either overconfidence or sentiment for the study of financial markets.

\section{APPENDIX}

To facilitate our proofs in what follows, some equilibrium concepts of the dynamic are in order. Say that a state $x^{*} \in \Delta=\left\{x(t) \in R_{+}^{2} \mid x_{1}(t)+x_{2}(t)=1\right\}$ is a dynamic equilibrium (a.k.a. steady state) for the dynamic $\dot{x}(t)$, if $\left.\dot{x}(t)\right|_{x(t)=x^{*}}=0$. Such states are steady in that $x(t)=x^{*}$ for all $t \in[0, \infty)$ iff $\left.\dot{x}(0)\right|_{x(0)=x^{*}}=0$. Say that a dynamic equilibrium $x^{*} \in \Delta$ is asymptotically stable if it has some open neighborhood $N\left(x^{*}\right)$ such that $\lim _{t \rightarrow \infty} x(t)=x^{*}$, if the initial state $x(0) \in$ $N\left(x^{*}\right) \cap \Delta$. Intuitively, the asymptotic stability requires a local pull toward the steady state following a small perturbation, and hence all states near a dynamic equilibrium will eventually evolve toward it.

Proof of theorem 1. Note that the homogenous profiles $(1,0)$ and $(0,1)$ are always steady states for the dynamic in (18) and the heterogeneous profile $\left(a_{2} /\left(a_{1}+a_{2}\right), a_{1} /\left(a_{1}+a_{2}\right)\right)$ is an interior steady state if the two return parameters, $a_{1}$ and $a_{2}$, have the same signs. To check the asymptotic stability, differentiate the dynamic $\dot{x}_{2}$ in (18) with respect to $x_{2}$ and evaluate the partial derivative at each steady state, respectively, as follows:

$$
\begin{gathered}
\frac{\partial \dot{x}_{2}}{\partial x_{2}}=-3\left(a_{1}+a_{2}\right) x_{2}^{2}+2\left(2 a_{1}+a_{2}\right) x_{2}-a_{1} \\
\left.\frac{\partial \dot{x}_{2}}{\partial x_{2}}\right|_{x_{2}=0}=-a_{1},\left.\quad \frac{\partial \dot{x}_{2}}{\partial x_{2}}\right|_{x_{2}=1}=-a_{2}, \quad \text { and }\left.\quad \frac{\partial \dot{x}_{2}}{\partial x_{2}}\right|_{x_{2}=\frac{a_{1}}{a_{1}+a_{2}}}=\frac{a_{1} a_{2}}{a_{1}+a_{2}} .
\end{gathered}
$$

A steady state is asymptotically stable iff the partial derivative evaluated at that state is negative. By (A2), the following results are obtained: $(1,0)$ is asymptotically stable if $a_{1}>0 ;(0,1)$ is asymptotically stable if $a_{2}>0 ;\left(a_{2} /\left(a_{1}+a_{2}\right), a_{1} /\left(a_{1}+\right.\right.$ $\left.a_{2}\right)$ ) is asymptotically stable if $a_{1}<0$ and $a_{2}<0$.

The results of the proof of theorem 1 are summarized as follows:

(I) If $a_{1}>0$ and $a_{2}<0$, then $\left(x_{1}, x_{2}\right)=(1,0)$ is the unique asymptotically stable equilibrium.

(II) If $a_{1}<0$ and $a_{2}>0$, then $\left(x_{1}, x_{2}\right)=(0,1)$ is the unique asymptotically stable equilibrium.

(III) If $a_{1}>0$ and $a_{2}>0$, then there exist two asymptotically stable equilibria such that

$$
\lim _{t \rightarrow \infty} x(t)= \begin{cases}(1,0) & \text { if } x_{2}(0) \in\left[0, \frac{a_{1}}{a_{1}+a_{2}}\right) \\ (0,1) & \text { if } x_{2}(0) \in\left(\frac{a_{1}}{a_{1}+a_{2}}, 1\right] .\end{cases}
$$


(VI) If $a_{1}<0$ and $a_{2}<0$, then $\left(x_{1}, x_{2}\right)=\left(a_{2} /\left(a_{1}+a_{2}\right), a_{1} /\left(a_{1}+a_{2}\right)\right)$ is the unique asymptotically stable equilibrium.

Proof of theorem 2.1. By (30), if $\rho^{*}<0$ or $0<\rho^{*}<\left((1+r)^{2}\left(\rho^{* 2}+\sigma_{\rho}^{2}\right)\right)$ / $\left(2 \gamma \sigma_{\rho}^{2}\right)$, then we have $E\left[R_{2}(x(t))\right]-E\left[R_{1}(x(t))\right]<0$ for $\forall x(t) \in \Delta=\{x(t) \in$ $\left.R_{+}^{2} \mid x_{1}(t)+x_{2}(t)=1\right\}$. To derive the parameter space for the second case, rearrange and write a quadratic function $f\left(\rho^{*}\right)$ as follows:

$$
f\left(\rho^{*}\right)=\rho^{* 2}-\frac{2 \gamma \sigma_{\rho}^{2}}{(1+r)^{2}} \rho^{*}+\sigma_{\rho}^{2} .
$$

A simple calculation shows that the function is greater than zero (and hence $\left.E\left[R_{2}(x(t))\right]-E\left[R_{1}(x(t))\right]<0\right)$ if either $\sigma_{\rho} \leq(1+r)^{2} / \gamma$ or $\rho^{*} \in\left(0, \rho_{-}^{*}\right) \cup$ $\left(\rho_{+}^{*}, \infty\right)$, where

$$
\begin{aligned}
& \rho_{-}^{*}=\frac{1}{2}\left(\frac{2 \gamma \sigma_{\rho}^{2}}{(1+r)^{2}}-\sqrt{\left(\frac{2 \gamma \sigma_{\rho}^{2}}{(1+r)^{2}}\right)^{2}-4 \sigma_{\rho}^{2}}\right) \quad \text { and } \\
& \rho_{+}^{*}=\frac{1}{2}\left(\frac{2 \gamma \sigma_{\rho}^{2}}{(1+r)^{2}}+\sqrt{\left(\frac{2 \gamma \sigma_{\rho}^{2}}{(1+r)^{2}}\right)^{2}-4 \sigma_{\rho}^{2}}\right) .
\end{aligned}
$$

Given that $E\left[R_{2}(x(t))\right]-E\left[R_{1}(x(t))\right]<0$, starting from any nonstationary states, the population share of noise traders will decline to zero in the long run. Thus, the unique asymptotically stable equilibrium is $\left(x_{1}, x_{2}\right)=(1,0)$.

On the other hand, if $\sigma_{\rho}>(1+r)^{2} / \gamma$ and $\rho^{*} \in\left(\rho_{-}^{*}, \rho_{+}^{*}\right)$, then the function $f\left(\rho^{*}\right)$ is less than zero, and hence the dynamic in (30) may have one interior steady state, $\left(x_{1}, x_{2}\right)=(1-\mu, \mu)$, where $\mu$ is given by $\mu=\left((1+r)^{2}\left(\rho^{* 2}+\sigma_{\rho}^{2}\right)\right) /$ $\left(2 \gamma \rho^{*} \sigma_{\rho}^{2}\right)$. In this case, the expected return differential, $E\left[R_{2}(x(t))\right]-E\left[R_{1}(x(t))\right]$, depends on the current population share relative to the interior steady state. If the current noise trader share is below the interior steady state, i.e., $x_{2}(t)<\mu$, then the expected return differential is negative and the population share of the noise traders will decline to zero in the long run. If the current noise trader share is above the interior steady state, i.e., $x_{2}(t)>\mu$, then the expected return differential is positive and the population share of the noise traders will increase to one. Thus, we obtain two asymptotically stable equilibria, $(1,0)$ and $(0,1)$, respectively.

The results of the proof of theorem 2.1 are summarized as follows: librium.

(I) If $\rho^{*}<0$, then $\left(x_{1}, x_{2}\right)=(1,0)$ is the unique asymptotically stable equi-

(II) If $\sigma_{\rho} \leq(1+r)^{2} / \gamma$ or $\rho^{*} \in\left(0, \rho_{-}^{*}\right) \cup\left(\rho_{+}^{*}, \infty\right)$, then $\left(x_{1}, x_{2}\right)=(1,0)$ is the unique asymptotically stable equilibrium. 
(III) If $\sigma_{\rho}>(1+r)^{2} / \gamma$ and $\rho^{*} \in\left(\rho_{-}^{*}, \rho_{+}^{*}\right)$, then there exist one unique interior steady state $(1-\mu, \mu)$ and two asymptotically stable equilibria such that

$$
\lim _{t \rightarrow \infty} x(t)= \begin{cases}(1,0) & \text { if } x_{2}(0) \in[0, \mu) \\ (0,1) & \text { if } x_{2}(0) \in(\mu, 1]\end{cases}
$$

Proof of theorem 2.2. By (29), $\rho^{*}<0 \Rightarrow E\left[R_{2}(x(t))\right]-E\left[R_{1}(x(t))\right]<0$ for $\forall x(t) \in \Delta=\left\{x(t) \in R_{+}^{2} \mid x_{1}(t)+x_{2}(t)=1\right\}$. Hence, the dynamic in (29) only has two steady states: $(1,0)$ and $(0,1)$. To check the asymptotic stability, differentiate the dynamic $\dot{x}_{2}$ in (29) with respect to $x_{2}$ and evaluate the partial derivative at each steady state, respectively, as follows (ignoring the constant $1 / c_{0}$ without loss of generality):

$$
\begin{gathered}
\left.\frac{\partial \dot{x}_{2}}{\partial x_{2}}\right|_{x_{2}=0}=\rho^{*} \\
\left.\frac{\partial \dot{x}_{2}}{\partial x_{2}}\right|_{x_{2}=1}=-\rho^{*}+\frac{\rho^{* 2}+\sigma_{\rho}^{2}}{2 \gamma\left(\frac{\sigma_{\rho}^{2}}{(1+r)^{2}}+\sigma_{\varepsilon}^{2}\right)}=E\left[\tilde{R}_{1, n}(0,1)\right]-E\left[\tilde{R}_{2, n}(0,1)\right] .
\end{gathered}
$$

A steady state is asymptotically stable iff the partial derivative evaluated at that state is negative. Hence $x(t)=(1,0)$ is the unique asymptotically stable equilibrium in category I in which $\rho^{*}<0$.

In category II (i.e., $\rho^{*}>0$ and $E\left[R_{2}(x(t))\right]-E\left[R_{1}(x(t))\right]>0$ for $\left.\forall x(t) \in \Delta\right)$, the dynamic again has two steady states: $(1,0)$ and $(0,1)$. Given that $\rho^{*}>0, x(t)=$ $(1,0)$ is not asymptotically stable by (A5). On the other hand, $(0,1)$ is asymptotically stable iff $E\left[\tilde{R}_{2}(0,1)\right]-E\left[\tilde{R}_{1}(0,1)\right]>0$ by (A6). This always holds in category II by its definition. Hence, $x(t)=(0,1)$ is the unique asymptotically stable equilibrium.

If $\rho^{*}>0$ and $g>0$, then $E\left[\tilde{R}_{2}(x(t))\right]-E\left[\tilde{R}_{1}(x(t))\right]=0$ may have at most two real roots $\mu_{L}$ and $\mu_{H}$, as defined in (31) and (32), for some $x(t) \in \Delta \backslash\{(1,0),(0,1)\}$. By definition, a positive real root is an interior steady state if it is bounded above by one. Hence, there are two possibilities for the existence of the interior states: (1) the lower root $\mu_{L}$ is the unique interior steady state in category III for $0<$ $\mu_{L}<1<\mu_{H}$, and (2) both roots $\mu_{L}$ and $\mu_{H}$ are interior steady states in category IV for $0<\mu_{L}<\mu_{H}<1$. To check the asymptotic stability for the interior steady states, compute

$$
\left.\frac{\partial \dot{x}_{2}}{\partial x_{2}}\right|_{x_{2}=\mu_{j}}=\frac{\mu_{j}\left(1-\mu_{j}\right)\left(\rho^{* 2}+\sigma_{\rho}^{2}\right)\left(\frac{\sigma_{\rho}^{2}}{(1+r)^{2}}-\frac{\sigma_{\varepsilon}^{2}}{\mu_{i}^{2}}\right)}{2 \gamma\left(\frac{\mu_{j} \sigma_{\rho}^{2}}{(1+r)^{2}}+\frac{\sigma_{\varepsilon}^{2}}{\mu_{i}}\right)^{2}}, \quad \text { where } j=L, H .
$$

Equation (A7) indicates that an interior steady state $\mu_{j}$ is negative iff $\mu_{j}<$ $(1+r) \sigma_{\varepsilon} / \sigma_{\rho}, j=L, H$. Given the existence of the two real roots, i.e., $g>0$, 
(31) and (32) imply the following two inequalities:

$$
\begin{gathered}
\mu_{L}<\frac{(1+r) \sqrt{16 \gamma^{2} \sigma_{\rho}^{2} \sigma_{\varepsilon}^{2} \rho^{* 2}}}{4 \gamma \sigma_{\rho}^{2} \rho^{*}}=\frac{(1+r) \sigma_{\varepsilon}}{\sigma_{\rho}} \\
\mu_{H}>\frac{(1+r)^{2}\left(\sigma_{\rho}^{2}+\rho^{* 2}\right)}{4 \gamma \sigma_{\rho}^{2} \rho^{*}}>\frac{(1+r) \sqrt{16 \gamma^{2} \sigma_{\rho}^{2} \sigma_{\varepsilon}^{2} \rho^{* 2}}}{4 \gamma \sigma_{\rho}^{2} \rho^{*}}=\frac{(1+r) \sigma_{\varepsilon}}{\sigma_{\rho}} .
\end{gathered}
$$

By (A7)-(A9), the lower root $\mu_{L}$ is asymptotically stable, but the higher root $\mu_{H}$ is not. Note that $(0,1)$ is asymptotically stable iff $E\left[\tilde{R}_{2}(0,1)\right]-E\left[\tilde{R}_{1}(0,1)\right]>0$ by (A6). Note also that $E\left[\tilde{R}_{2}(x(t))\right]-E\left[\tilde{R}_{1}(x(t))\right]$ is a convex function, given $\rho^{*}>0$. Thus, a simple inspection of the convex function for $x_{2}(t) \in[0,1]$ shows that (1) $E\left[\tilde{R}_{2}(0,1)\right]-E\left[\tilde{R}_{1}(0,1)\right]<0$ if there exists only one interior steady state $\mu_{L}$ (category III) and (2) $E\left[\tilde{R}_{2}(0,1)\right]-E\left[\tilde{R}_{1}(0,1)\right]>0$ if there exist two interior steady states (category IV). Hence, $x(t)=(0,1)$ is an asymptotically stable equilibrium in category IV, but not in category III. Finally, given that $\rho^{*}>0, x(t)=(1,0)$ is not asymptotically stable in either category III or IV by (A5). Therefore, we obtain the desired results in Theorem 2.

The results of the proof of theorem 2.2 are summarized as follows:

(I) If $\rho^{*}<0$, then $\left(x_{1}, x_{2}\right)=(1,0)$ is the unique asymptotically stable equilibrium.

(II) If $\rho^{*}>0$ and $E\left[\tilde{R}_{2}(x(t))\right]-E\left[\tilde{R}_{1}(x(t))\right]>0$ for $\forall x(t) \in \Delta=\{x(t) \in$ $\left.R_{+}^{2} \mid x_{1}(t)+x_{2}(t)=1\right\}$, then $\left(x_{1}, x_{2}\right)=(0,1)$ is the unique asymptotically stable equilibrium.

(III) If $\rho^{*}>0$ and $0<\mu_{L}<1<\mu_{H}$, then $\left(x_{1}, x_{2}\right)=\left(1-\mu_{L}, \mu_{L}\right)$ is the unique asymptotically stable equilibrium.

(IV) If $\rho^{*}>0$ and $0<\mu_{L}<\mu_{H}<1$, then there exist two asymptotically stable equilibria such that

$$
\lim _{t \rightarrow \infty} x(t)= \begin{cases}\left(1-\mu_{L}, \mu_{L}\right) & \text { if } x_{2}(0) \in\left[0, \mu_{H}\right) \\ (0,1) & \text { if } x_{2}(0) \in\left(\mu_{H}, 1\right] .\end{cases}
$$

\section{REFERENCES}

Alpert, M., and Raiffa, H. (1959). A progress report on the training of probability assessors, in "Judgment under Uncertainty: Heuristics and Biases" (D. Kahneman, P. Slovic, and A. Tversky, Eds.), Cambridge University Press, Cambridge, MA, 1982.

Barberis, N., Shleifer, A., and Vishny, R. (1998). A model of investor sentiment, J. Finan. Econ. 49, 307-343. 
Bernardo, A., and Welch, I. (2000). “On the Evolution of Overconfidence and Entrepreneurs,” Working Paper, Yale University.

Black, F. (1986). Noise, J. Finance 41, 529-543.

Blume, L., and Easley, D. (1992). Evolution and market behavior, J. Econ. Theory 58, 9-40.

Campbell, J. Y., and Kyle, A. S. (1993). Smart money, noise trading, and stock price behavior, Rev. Econ. Stud. 60, 1-34.

Daniel, K., Hirshleifer, D., and Subrahmanyam, A. (1998). Investor psychology and security market under- and overreactions, J. Finance 53, 1839-1885.

Daniel, K., Hirshleifer, D., and Subrahmanyam, A. (2001). Covariance risk, mispricing, and the crosssection of security returns, J. Finance, in press.

De Bondt, W. F. M., and Thaler, R. H. (1995). Financial decision-making in markets and firms: A behavioral perspective, in "Finance, Handbooks in Operations Research and Management Science" (R. A. Jarrow, V. Maksimovic and W. T. Ziemba, Eds.), Vol. 9, North-Holland, Amsterdam.

De Long, J. B., Shleifer, A., Summers L. H., and Waldmann, R. J. (1989). The size and incidence of the losses from noise trading, J. Finance 44, 681-696.

De Long, J. B., Shleifer, A., Summers, L. H., and Waldmann, R. J. (1990). Noise trader risk in financial markets, J. Polit. Econ. 98, 703-738.

De Long, J. B., Shleifer, A., Summers, L. H., and Waldmann, R. J. (1991). The survival of noise traders in financial markets, J. Bus. 64, 1-19.

Einhorn, H., and Hogarth, R. (1978). Confidence in judgment: Persistence of the illusion of validity, Psych. Rev. 85, 395-416.

Friedman, D. (1991). Evolutionary games in economics, Econometrica 59, 637-666.

Friedman, M. (1953). "Essays in Positive Economics,” University of Chicago Press, Chicago.

Gervais, S., and Odean, T. (2001). Learning to be overconfident, Rev. Finan. Stud. 14, 1-27.

Goel, A. M., and Thakor, A. V. (2000). “Rationality, Overconfidence and Leadership,” Working Paper, University of Michigan.

Hirshleifer, D., and Luo, G. Y. (2001). On the survival of overconfident traders in a competitive security market, J. Finan. Markets 4, 73-84.

Hirshleifer, D., Subrahmanyam, A., and Titman, S. (1994). Security analysis and trading patterns when some investors receive information before others, J. Finance 49, 1665-1698.

Kahneman, D., Slovic, P., and Tversky, A., Eds. (1982). "Judgment under Uncertainty: Heuristics and Biases," Cambridge University Press, Cambridge, UK.

Kyle, A. S. (1985). Continuous auctions and insider trading, Econometrica 53, 1315-1336.

Kyle, A. S., and Wang, F. A. (1997). Speculation duopoly with agreement to disagree: Can overconfidence survive the market test? J. Finance 52, 2073-2090.

Lakonishok, J., Shleifer, A., and Vishny, R. W. (1992). "The Structure and Performance of the Money Management Industry,” Brookings Papers, Microeconomics, pp. 339-391.

Langer, E. J., and Roth, J. (1975). Heads I win tails it's chance. The illusion of control as a function of the sequence of outcomes in a purely chance task, J. Personality Social Psych. 32, 951-955.

Maynard Smith, J. (1982). "Evolution and the Theory of Games," Cambridge University Press, Cambridge, UK.

Milgrom P., and Stokey, N. (1982). Information, trade and common knowledge, J. Econ. Theory 26, 17-27.

Odean, T. (1998). Volume, volatility, price, and profit when all traders are above average, J. Finance 53, 1887-1934.

Oskamp, S. (1965). Overconfidence in case study judgments, J. Consulting Psych. 29, 261-265.

Palomino, F. (1996). Noise trading in small markets, J. Finance 51, 1537-1550. 
Russell, T., and Thaler, R. H. (1985). The relevance of quasi-rationality in competitive markets, Am. Econ. Rev. 75, 1071-1082.

Samuelson, P. A. (1971). The 'fallacy' of maximizing the geometric mean in long sequences of investing or gambling, Proc. National Acad. Sci. 68, 2493-2496.

Samuelson, P. A. (1977). St. Petersburg paradoxes. J. Econ. Lit. 15, 24-55.

Shiryayev, A. N. (1984). "Probability," Springer-Verlag, New York.

Taylor, P. D., and Jonker, L. B. (1978). Evolutionary stable strategies and game dynamics, Math. Biosci. 40, 145-156.

Van Damme, E. (1987). "Stability and Perfection of Nash Equilibria," Springer-Verlag, Berlin.

Vega-Redondo, F. (1996). "Evolution, Games, and Economic Behaviour," Oxford University Press, Oxford.

Wang, F. A. (1998). Strategic trading, asymmetric information and heterogeneous prior beliefs, J. Finan. Markets 1, 321-352.

Wang, F. A. (2000). "Speculative Noise Trading in Financial Markets," Working Paper, Rice University. Weibull, J. W. (1995). "Evolutionary Game Theory,” The MIT Press, Cambridge, MA. 